\title{
Challenges in the Treatment of Chronic Wounds
}

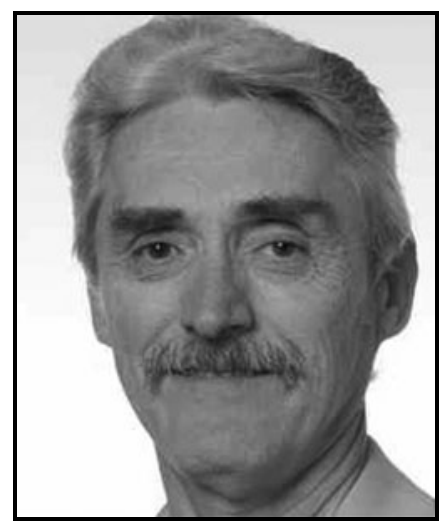

Robert G. Frykberg, DPM, MPH

Submitted for publication January 23, 2015 Accepted in revised form May 4, 2015.

${ }^{*}$ Correspondence: Phoenix VA Health Care System, 650 East Indian School Road, Phoenix AZ 85012 (e-mail: robert.frykberg@va.gov).

\author{
Robert G. Frykberg* and Jaminelli Banks \\ Phoenix VA Health Care System, Phoenix, Arizona.
}

Significance: Chronic wounds include, but are not limited, to diabetic foot ulcers, venous leg ulcers, and pressure ulcers. They are a challenge to wound care professionals and consume a great deal of healthcare resources around the globe. This review discusses the pathophysiology of complex chronic wounds and the means and modalities currently available to achieve healing in such patients.

Recent Advances: Although often difficult to treat, an understanding of the underlying pathophysiology and specific attention toward managing these perturbations can often lead to successful healing.

Critical Issues: Overcoming the factors that contribute to delayed healing are key components of a comprehensive approach to wound care and present the primary challenges to the treatment of chronic wounds. When wounds fail to achieve sufficient healing after 4 weeks of standard care, reassessment of underlying pathology and consideration of the need for advanced therapeutic agents should be undertaken. However, selection of an appropriate therapy is often not evidence based.

Future Directions: Basic tenets of care need to be routinely followed, and a systematic evaluation of patients and their wounds will also facilitate appropriate care. Underlying pathologies, which result in the failure of these wounds to heal, differ among various types of chronic wounds. A better understanding of the differences between various types of chronic wounds at the molecular and cellular levels should improve our treatment approaches, leading to better healing rates, and facilitate the development of new more effective therapies. More evidence for the efficacy of current and future advanced wound therapies is required for their appropriate use.

\section{SCOPE AND SIGNIFICANCE}

CHRONIC LOWER EXTREMITY ulcers are those that do not progress through the healing process in a timely manner and have become a major challenge to healthcare systems worldwide. In the United States alone, these wounds affect an estimated 2.4-4.5 million people. ${ }^{1,2}$ Chronic leg and foot ulcers occur in many adults with vascular disease or diabetes and are attributed to chronic venous insufficiency, arterial disease, prolonged pressure, or neuropathy. ${ }^{2}$ These ulcers last on average 12 to 13 months, recur in up to $60 \%$ to $70 \%$ of patients, can lead to loss of function and decreased quality of life, and are a significant cause of morbidity. ${ }^{2,3}$ Predominantly a condition of the elderly, chronic wounds are becoming more prevalent and

(C) Robert G. Frykberg and Jaminelli Banks 2015; Published by Mary Ann Liebert, Inc. This Open Access article is distributed under the terms of the Creative Commons Attribution Noncommercial License (http://creativecommons.org/licenses/by-nc/4.0/) which permits any noncommercial use, distribution, and reproduction in any medium, provided the original author(s) and the source are credited. 
more difficult to treat and are associated with high treatment costs. ${ }^{4}$ The care of chronic wounds has become its own specialty, with providers often using advanced therapies, including growth factors, extracellular matrices (ECMs), engineered skin, and negative pressure wound therapy (NPWT) ${ }^{5}$ Care for such conditions has been reported to cost $2 \%$ to $3 \%$ of the healthcare budgets in developed countries. ${ }^{2,3}$

Chronic wounds can be classified as vascular ulcers (e.g., venous and arterial ulcers), diabetic ulcers, and pressure ulcers (PUs). ${ }^{6}$ Some common features shared by each of these wounds include prolonged or excessive inflammation, persistent infections, formation of drug-resistant microbial biofilms, and the inability of dermal and/or epidermal cells to respond to reparative stimuli. ${ }^{7-11}$ In aggregate, these pathophysiologic phenomena result in the failure of these wounds to heal. The underlying pathologies, however, differ among various types of chronic wounds.

This review provides a brief overview of the pathophysiology of chronic wound healing and discusses the established tenets and advanced treatment of chronic wounds, with an emphasis on diabetic foot ulcers (DFUs). Overcoming the factors that contribute to delayed healing is a part of the comprehensive approach to wound care and presents the primary challenges to the treatment of chronic wounds.

\section{TRANSLATIONAL RELEVANCE}

This review provides researchers with a comprehensive discussion of the pathophysiology and approaches for the evaluation and treatment of chronic wounds from the perspective of an experienced wound care physician. A better understanding of the challenges physicians face currently with chronic wounds should facilitate the development of new wound care products.

This review also demonstrates the lack of available evidence demonstrating efficacy for a majority of existing advanced wound care products. This fact should be taken into consideration by researchers during the development of clinical programs for wound care products.

\section{CLINICAL RELEVANCE}

Understanding and addressing the challenges in the treatment of chronic wounds will lead to a better clinical outcome (faster and more durable wound closure), resulting in improved patient quality of life and reduced healthcare costs. This review provides a current expert opinion and can be used as a guideline for evaluation and appropriate treatment selection for nonhealing wounds.

\section{DISCUSSION}

\section{Physiology of wound healing}

The physiological process of wound healing is achieved through four temporarily and spatially overlapping phases: hemostasis, inflammation, proliferation, and remodeling phases. ${ }^{12,13} \mathrm{Im}$ mediately after injury, hemostasis occurs and is characterized by vasoconstriction and blood clotting, which prevents blood loss and provides the provisional matrix for cell migration. Platelets secrete growth factors and cytokines attract fibroblasts, endothelial cells, and immune cells to initiate the healing process. The subsequent inflammation phase lasts up to 7 days. The predominant cells at work in this phase are phagocytic cells, such as neutrophils and macrophages. Neutrophils release reactive oxygen species (ROS) and proteases that prevent bacterial contamination and cleanse the wound of cellular debris. Blood monocytes arrive at the wound site and differentiate into tissue macrophages. The latter not only remove bacteria and nonviable tissue by phagocytosis but also release various growth factors and cytokines recruiting fibroblasts, endothelial cells, and keratinocytes to repair the damaged blood vessels. As the inflammatory phase subsides accompanied by apoptosis of immune cells, the proliferation phase begins. This phase is primarily characterized by tissue granulation, formation of new blood vessels (angiogenesis), and epithelialization. The last phase occurs once the wound has closed and may last 1-2 years or longer. During this phase, the provisional matrix is remodeled into organized collagen bundles. ${ }^{14,15}$

\section{Pathophysiology of chronic wounds}

Chronic wounds are defined as wounds that fail to proceed through the normal phases of wound healing in an orderly and timely manner. Often, chronic wounds stall in the inflammation phase of healing. Despite differences in etiology at the molecular level, chronic wounds share certain common features, including excessive levels of proinflammatory cytokines, proteases, ROS, and senescent cells, as well as the existence of persistent infection, and a deficiency of stem cells that are often also dysfunctional (Fig. 1).

Due to repeated tissue injury, microorganisms and platelet-derived factors, such as transforming growth factor- $\beta$ (TGF- $\beta$ ) or ECM fragment molecules, stimulate the constant influx of immune cells; the proinflammatory cytokine cascade therefore becomes amplified and persists for a prolonged time, leading to elevated levels of proteases. In acute wounds, proteases are tightly 


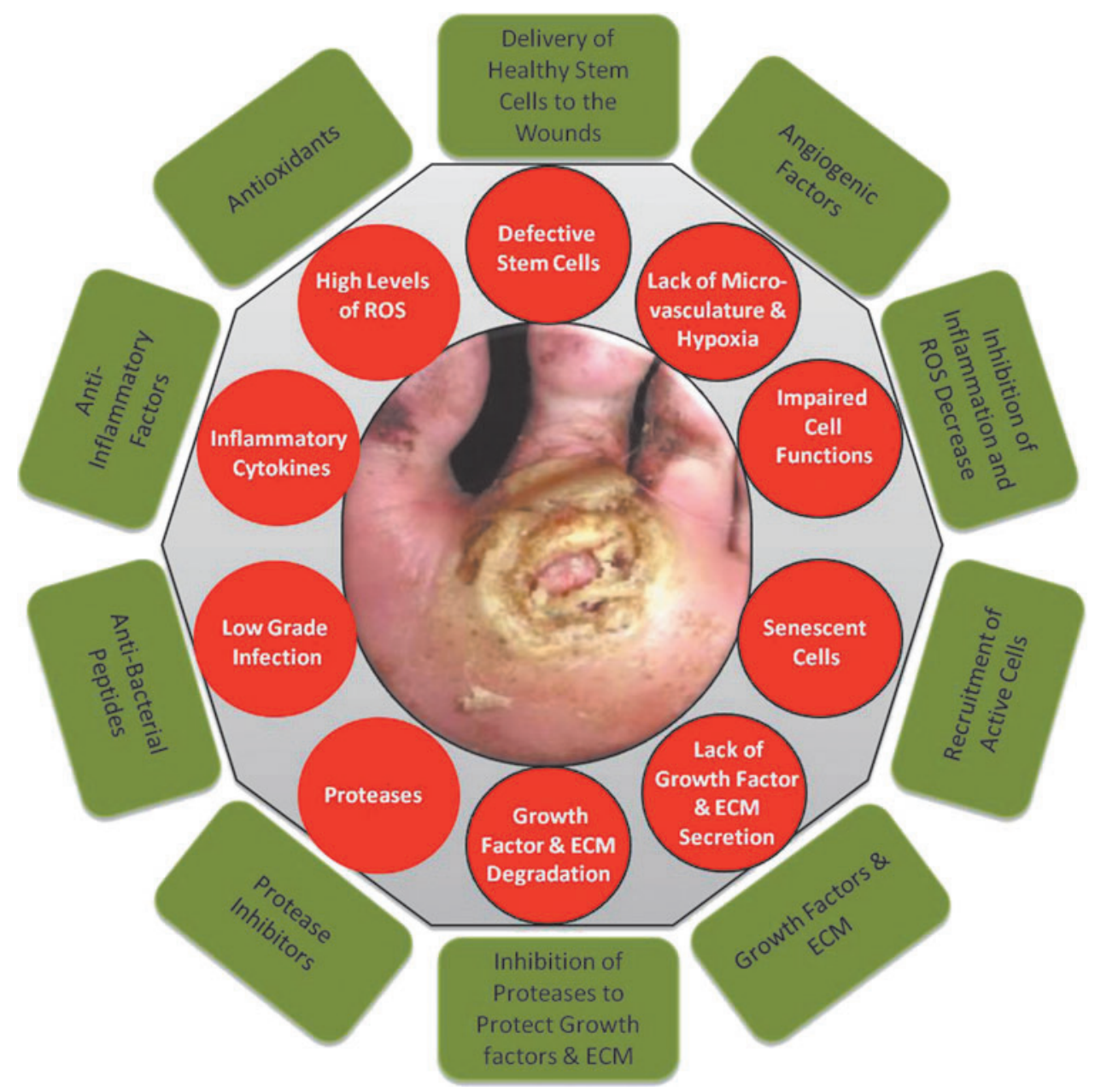

Figure 1. Molecular and cellular deficiencies in chronic wounds (red circles) and factors required to overcome them (green rectangles). Nonhealing ulcers and wounds represent a failure to achieve complete reepithelialization in the appropriate temporal sequence of tissue repair. Such wounds are characterized by excessive inflammation (including elevated levels of proteases, ROS, and inflammatory cytokines), by senescent cell populations with impaired proliferative and secretory capacities, and by defective MSCs. Excessive inflammation leads to degradation of newly synthesized growth factors and ECM. There is a need to restore the proper balance of cytokines, growth factors, and proteases, to recruit functional cells (epithelial cells, fibroblasts, and endothelial cells) to the wound area, and to deliver healthy functional MSCs directly to the wound to compensate for the patient's own dysfunctional stem cells. ECM, extracellular matrix; MSCs, mesenchymal stem cells; ROS, reactive oxygen species.

regulated by their inhibitors. In chronic wounds, protease levels exceed that of their respective inhibitors, leading to destruction of ECM and degradation of growth factors and their receptors. The proteolytic destruction of ECM not only prevents the wound from moving forward into the proliferative phase but also attracts more inflammatory cells, thus amplifying the inflammation cycle. ${ }^{16}$

Immune cells produce ROS, which in low concentrations provides defense against microorganisms. In chronic wounds, however, the predominant hypoxic and inflammatory environment increases ROS production, which damages ECM proteins and causes cell damage. This sequence of events leads to an enhanced stimulation of proteases and inflammatory cytokines. ${ }^{17}$ It has been suggested in an animal model that application of strong antioxidants reduces ROS to normal levels, which results in the reverse of the chronicity of wounds and improves healing. ${ }^{18}$

Furthermore, chronic wounds are characterized by senescent cell populations with impaired proliferative and secretory capacities, rendering them unresponsive to typical wound healing signals. ${ }^{15}$ It has been reported that fibroblasts from venous and PUs are senescent and have a diminished ability to proliferate. This diminished proliferative capacity is directly correlated with the failure of a wound to heal. ${ }^{19-21}$ Accumulated data also indicate that chronic wounds contain senescent keratinocytes, endothelial cells, fibroblasts, and macrophages. ${ }^{22-25}$ The senescent phenotype of cells in chronic wounds 
is attributed to oxidative stress that leads to DNA damage-related cell cycle arrest or to abnormal metabolic changes in diabetic patients, which results in defects in intracellular biochemical pathways such as the GSK-3 $\beta / \mathrm{Fyn} / \mathrm{Nrf2}$ pathway. ${ }^{24,26}$

In recent years, mesenchymal stem cells (MSCs) have been shown to play an important role in wound healing. ${ }^{27}$ These cells can be recruited into the circulation in response to injury. Subsequently, they are found to engraft into the remodeling microvasculature. Nonetheless, it has also been shown that stem cells in animals and patients with diabetes or chronic wounds are both deficient and defective. ${ }^{27-29}$ Thus, these patients may require a direct delivery of healthy donor-derived functional MSCs to overcome this deficiency and achieve wound healing. ${ }^{30}$

Nonhealing ulcers and wounds represent a failure to achieve complete reepithelialization in the appropriate temporal sequence of tissue repair. ${ }^{31}$ Understanding the underlying molecular and physiologic perturbations of nonhealing wounds, one can appreciate the necessity to modify these wounds toward the characteristics of an acute healing wound. The need to restore the proper balance of cytokines, growth factors, proteases, and metabolically competent cells is illustrated in Fig. $1{ }^{15}$

\section{Patient and wound assessment}

The care for chronic wounds therefore relies upon basic tenets that aim to not only remove or ameliorate the etiologic causes but also to address underlying systemic and metabolic perturbations such as infection or peripheral arterial disease. Proper care of the wound is facilitated initially by employing thorough patient and wound assessment. Factors contributing to the development or recalcitrance of the wounds are then addressed accordingly. Concurrent with the management of associated complications or etiologic factors, wound bed preparation plays a key role in encouraging the proper environment in which tissue repair can take place. Of course, appropriate diagnosis is mandatory to establish the etiology of the nonhealing wound. DFUs, venous leg ulcers (VLUs), PUs, post surgical wounds, and wound dehiscences are the most commonly seen wounds in wound care practice. Atypical wounds such as pyoderma gangrenosum can also be very challenging. Each has its own underlying etiopathogenesis that must be addressed upon initial presentation. Nonetheless, the clinician must be diligent in taking care to rule out the presence of malignancy in the wound either secondarily due to malignant degeneration as in the case of squamous cell carcinoma or as a primary lesion (Fig. 2A). Aside from neoplastic lesions, the basic tenets of wound assessment and care as presented in Table 1 serve as a guide to facilitate the management of most chronic wounds.

Patient assessment. Patient assessment must start with a thorough patient history to determine medical comorbidities, contributing factors possibly leading to the chronic wound, prior trauma, prior history of wounds, current medications, and allergies. Obviously, the presence of diabetes mellitus with neuropathy will be important to note for those patients presenting with a DFU as will a history of deep venous thrombosis for those presenting with a suspected VLU. The importance of
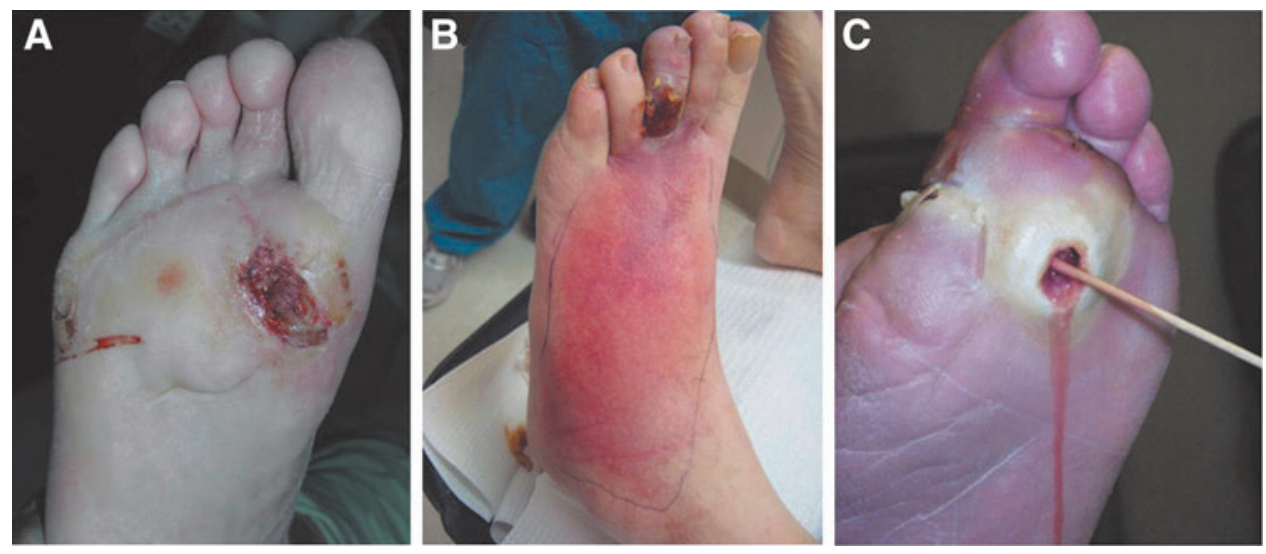

Figure 2. (A) Recurrent plantar ulcer not responsive to offloading. Biopsy revealed amelanotic melanoma. The clinician must be diligent in taking care to rule out the presence of malignancy in the wound either secondarily due to malignant degeneration as in the case of squamous cell carcinoma or as a primary lesion. (B) Cellulitis from infected digital wound with associated ischemia. Significant erythema can indicate cellulitis or infection requiring immediate hospitalization or might be an indicator of significant ischemia (dependent rubor). (C) Probe-to-bone test. If the bone is directly appreciated at the base of a wound, osteomyelitis is likely. A positive probe-to-bone test has a high predictive value for underlying osteomyelitis, even in the absence of acute signs of deep infection. 
Table 1. Basic tenets of wound care

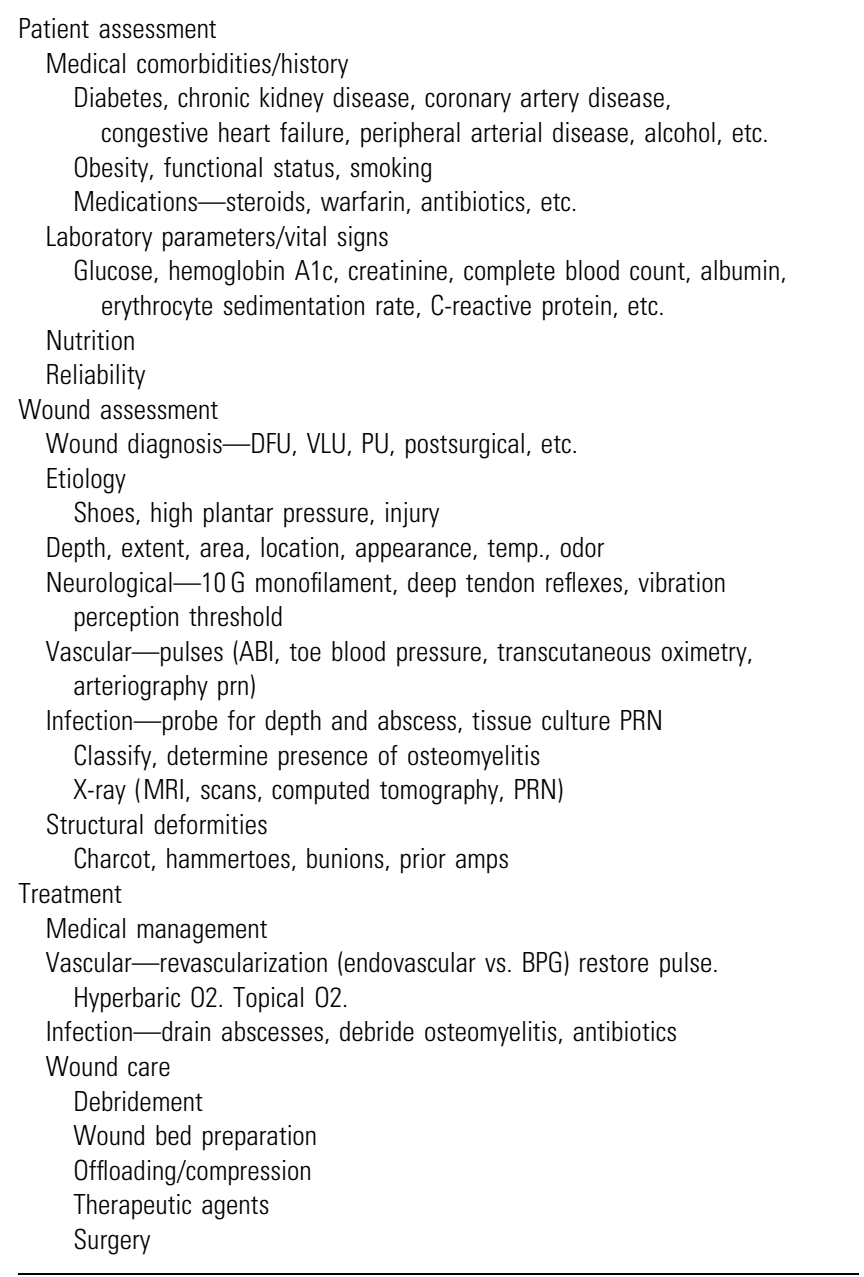

$\mathrm{ABI}$, ankle-brachial indices; $\mathrm{BPG}$, bypass graft; DFU, diabetic foot ulcer; $\mathrm{MRI}$, magnetic resonance imaging; PRN, as necessary; PU, pressure ulcer; $\mathrm{VLU}$, venous leg ulcer.

taking a medical history cannot be overemphasized. Laboratory studies at the time of presentation, including hematology, serum chemistries, and nutritional parameters, will also provide useful information to supplement initial impressions. ${ }^{32}$ An assessment of the patients' living situation and their likely reliability in following prescribed treatments is important in the actual determination of which therapies should be employed to manage the wound(s).

Wound assessment. Assessment of the wound actually begins during the initial encounter with the patient, whereby his/her general appearance is noted as well as that of the wound itself. Morbid obesity or, conversely, a painfully thin patient body habitus is a clue to nutritional status that will have a bearing on treatment protocols as well as possibly on outcomes. A visual inspection of the wound will immediately identify very important attributes that will guide further evaluation and treatment.
Obvious necrosis or gangrene portends a much more serious complexity, while a healthy granular appearance might preclude a wound complicated by significant ischemia. Significant erythema, on the other hand, can indicate cellulitis or infection requiring immediate hospitalization or might be an indicator of significant ischemia (dependent rubor) (Fig. 2B). Nonetheless, an initial visual impression of the wound provides important clues not only to the etiology of the lesion but also to its complexity.

Depth, extent (size), location, general appearance, odor, and notation of exudates are all essential components of wound evaluation and need to be recorded at baseline. ${ }^{33}$ Probing the wound will determine its depth of penetration and any tracking along tendon sheaths or tissue planes. A positive probe-to-bone (PTB) test has a high predictive value for underlying osteomyelitis even in the absence of acute signs of deep infection (Fig. 2C). ${ }^{34,35}$ A neurological evaluation should be performed to assess the presence and extent of neuropathy since this factor not only predisposes a patient to DFUs but is also a major risk factor for diabetes-related lower extremity amputation. ${ }^{36-38}$

A vascular examination is important for any type of chronic wound, but assessment of arterial perfusion is especially important for DFU patients since this parameter will drive all subsequent therapies and outcomes. Palpation of pulses commences initially, recognizing that this assessment can be highly variable among different clinicians. $^{39,40}$ Medial arterial calcification renders pulse palpation to be difficult even in the presence of adequate perfusion to the foot. Nonetheless, ankle-brachial indices (ABI) should be obtained at baseline for most patients for whom there is any question of a pulse deficit. Despite the falsely elevated $A B I$ levels that medial arterial calcification produces, the American Diabetes Association has recommended that this diagnostic test be performed on diabetic patients over 50 years of age and whenever clinical circumstances (such as in the case of DFU) dictate this evaluation. ${ }^{39}$ Regardless, when the ABI is below 0.9 , the patient should be considered to have impaired arterial perfusion. To augment ankle-brachial studies, toe blood pressure readings, pulse volume recordings, transcutaneous oxygen measurements, and skin perfusion pressure measurements have been recommended as valid benchmarks for the prediction of wound healing. ${ }^{41,42}$ Whenever peripheral arterial disease is suspected or confirmed by the noninvasive tests above, a referral to a vascular surgeon or interventionist is indicated for angiography and revascularization. Limb salvage rates have been 
reported as high as $80 \%$ for ischemic foot ulcers undergoing revascularization. ${ }^{43-46}$

Venous ulcers are obviously different from arterial wounds and require a different series of diagnostic testing to confirm superficial or deep venous reflux, perforator incompetence, and chronic (or acute) venous thrombosis. Venous duplex ultrasound, plethysmography, and other venous reflux tests are the mainstays of diagnosis. ${ }^{47,48}$ Notwithstanding, mixed arterial and venous disease is always a concern for management that requires a combination of both arterial and venous noninvasive testing. ${ }^{49}$

Ascertainment of infection and determination of its severity are also critical for appropriate wound management and classification. ${ }^{33}$ As previously mentioned, a positive PTB test is a good indicator of underlying bone infection, especially in the presence of acute signs of infection. ${ }^{35}$ When signs of infection at the wound are present, tissue cultures are indicated to guide specific antimicrobial treatment. In contrast, clinically uninfected wounds should not be cultured since such cultures will yield growth of contaminants that need not be treated. ${ }^{50}$ Unfortunately, osteomyelitis can exist at the base of a wound without clinical signs of infection. Therefore, plain radiographs are necessary to rule out underlying bone changes or foreign bodies (or gas when clinical infection is present). However, the specificity $(75-83 \%)$ of plain radiographs for the detection of osteomyelitis is higher than its sensitivity (43-75\%); because of this, the use of other imaging methods are often required. ${ }^{51}$ Serial plain radiography taken every $2-4$ weeks is more useful than a single plain image due to delayed changes associated with infection progression. Serial plain radiography has greater sensitivity and specificity and is recommended when access to advanced imaging is limited. ${ }^{50}$ Again, exposure of bone or a positive PTB test should prompt suspicion for bone infection and warrant further diagnostic testing. When X-rays are negative, but suspicion is high for bone infection, advanced imaging, such as nuclear medicine scans, magnetic resonance imaging, or computed tomography, is indicated to confirm the diagnosis and the extent of involvement. ${ }^{33,50}$

Important for determining the etiology of foot wounds as well as for long-term management, structural deformities must be identified. Hammertoes, bunions, and especially Charcot deformities are important determinants of DFUs in association with neuropathy; these deformities are sites of increased pressure that must be ameliorated to provide for subsequent healing and prevention of recurrence. ${ }^{33}$ Similarly, the etiology of the wounds must be ascertained and thereby removed to successfully administer treatment. Foot ulcers are often the result of shoe pressure, repetitive plantar stress, or injury, while VLUs are obviously the result of increased venous pressure and valvular incompetency.

Chronic wounds, following their systematic assessment, should be classified according to one of the published (and preferably validated) classification systems. For DFUs, the Wagner, University of Texas, and PEDIS classification systems each have their place and have been embraced by the wound care community. ${ }^{52-54}$ VLUs are classified by the CEAP classification system and PUs by the NPUAP classification schemes. ${ }^{55,56}$ Classification can ultimately guide treatment by prompting systematic evaluation of important underlying components and, furthermore, can predict outcomes based on the severity of the disease. ${ }^{57}$

Imaging is a valuable method for assessment of the wound healing process. Biopsy of wound tissue is considered the gold standard for measuring tissue morphological changes. The usual analysis involves tissue staining with hematoxylin and eosin, which is examined under light microscopy. However, it is an invasive and time-consuming method. The invasiveness of the method is the primary reason for the development and implementation of noninvasive optical imaging techniques. Currently, there are many different noninvasive methods, including laser Doppler imaging, indocyanine green videoangiography, near-infrared spectroscopy, in vivo capillary microscopy, orthogonal polarization spectral imaging, reflectancemode confocal microscopy, hyperspectral imaging, optical coherence tomography, laser speckle imaging, photoacoustic microscopy, and others. Although the majority of these methods have more utility in basic research, several noninvasive imaging techniques are already in use for assessment of burns and chronic wounds. ${ }^{58-62}$ These published reports show the potential utility of noninvasive imaging as diagnostic and prognostic tools of the future to prevent the incidence of ulceration, diagnose infections, monitor complications and progress of treatment, and predict treatment outcomes.

\section{Basic tenets of treatment of chronic wounds}

Managing chronic wounds, although often times challenging, need not be considered a daunting task if basic principles of care are routinely followed. A thorough assessment of the patient and wound will guide subsequent treatment by elucidating underlying areas of concern that need to be specifically addressed. Therefore, a systematic 
approach to both assessment and treatment should most often lead to favorable outcomes. Due to the frequent complexity of patients and wounds, a multidisciplinary approach to management has been proven highly successful and is widely recommended. ${ }^{33,63,64}$

Medical/holistic management of the patient must commence concurrently with wound management. Diabetic patients frequently need improved control of their hyperglycemia, renal insufficiency, nutrition, and other associated medical comorbidities that may adversely affect the healing of their wound(s). Patients with a VLU might often have hemodynamic perturbations requiring improved medical management, while PU patients, often bedridden from intercurrent illness, will have significant nutritional deficits that need to be corrected to optimize tissue repair. ${ }^{65,66}$

The vascular examination performed during the wound assessment will have determined the need for necessary interventions. ${ }^{40}$ Since many DFUs have a component of vascular insufficiency, referral to a vascular surgeon or vascular interventionist for arterial imaging (angiography, duplex scanning, etc.) and subsequent revascularization need to take place early in the course of treatment. The exact roles of endovascular and open bypass procedures are still evolving, but are primarily determined by arterial anatomy, wound severity, and patient comorbidities. ${ }^{67,68}$ The ultimate goal is to restore a palpable pulse in the affected foot. In some limited cases where revascularization has failed or is not feasible, hyperbaric oxygen therapy (HBOT) might be indicated. ${ }^{69,70}$ Topical oxygen therapy, long criticized as having no role in this regard, is emerging again as an adjunctive measure to improve tissue oxygenation. ${ }^{71,72}$ In contrast, venous insufficiency must be addressed initially with adequate compression wrapping with or without intermittent pneumatic compression to counteract the detrimental effects of the venous hypertension causing associated VLUs. ${ }^{49}$ Where compression therapy is ineffective or for recurrent VLUs due to significant venous disease, surgical intervention on the superficial, deep, and/or incompetent perforators is indicated. ${ }^{47,49}$ Again, care must be taken to identify mixed arterial and venous disease in such circumstances since the associated arterial insufficiency complicates customary treatment protocols for venous ulcerations.

Infection is similarly an important risk factor for wound healing failure and, in the case of DFUs, for subsequent lower extremity amputation. ${ }^{73,74}$ Even excessive bioburden can inhibit normal progression to wound healing. ${ }^{75}$ While acutely infected wounds are easily diagnosed, neuropathy can mask the presence of deep infections or abscess. Hence, clinical suspicion must remain high when insensate patients complain of pain or flu-like symptoms. Once diagnosed, infection complicating chronic wounds must be treated aggressively. This includes thorough debridement, surgical drainage of abscesses, debridement of infected bone, and tissue culture-guided antimicrobial therapy. As previously mentioned, clinically noninfected ulcers should not be cultured nor treated with systemic antimicrobial therapy. ${ }^{50}$ However, if osteomyelitis is suspected, bone culture, followed by specific antimicrobial therapy (and perhaps surgery), is warranted for this recalcitrant infection. ${ }^{76}$

Specific wound care or wound bed preparation commences concurrently with the aforementioned interventions when feasible. ${ }^{15,75,77}$ Revascularization, however, often follows control of infection and initiation of wound care procedures. The acronym TIME has been used over the last decade or so to facilitate an organized approach to wound bed preparation and has been summarized nicely by Leaper et al. ${ }^{78-80}$ This acronym refers to Tissue assessment and management, Infection / Inflammation management, Moisture imbalance management, and Edge of wound observation and management (Table 2). The TIME principles are an integral, although incomplete, part of this discussion and incorporate the basic tenets of wound care that are critical for managing chronic wounds.

Debridement has long been recognized as a critical component for wound care and has been shown by several investigators to expedite healing. ${ }^{81,82}$ Sharp debridement removes nonviable tissue and slough along with bacterial biofilms that prolong the inflammatory response in the chronic wound. ${ }^{75}$ In effect, thorough debridement converts the chronic wound from one that is excessively inflamed, as previously described, to more of an acute profile that can jump-start the wound toward a healing trajectory. ${ }^{15,77}$ While sharp debridement is considered to be the most efficient way to debride a

Table 2. TIME principles of wound bed preparation

Tissue: assessment and debridement of nonviable or foreign material (including host necrotic tissue, adherent dressing material, multiple organism-related biofilm, or slough, exudate, and debris) on the surface of the wound.

Infection/inflammation: assessment of the etiology of each wound, need for topical antiseptic and/or systemic antibiotic use to control infection, and management of inappropriate inflammation unrelated to infection.

Moisture imbalance: assessment of the etiology and management of wound exudate.

Edge of wound: assessment of nonadvancing or undermined wound edges (and state of the surrounding skin).

Revised based on Leaper et al. ${ }^{78}$ 
wound (with scalpel, curette, tissue nippers, etc.), hydrosurgical or ultrasonic debridement can also be used in this regard. ${ }^{77}$ The term ulcerectomy has been used to denote complete excision of ulcers down to healthy bleeding tissue, resulting in expedited healing of DFUs. ${ }^{83}$ Maintenance debridement with enzymes (collagenase) is frequently used between clinic visits to gently remove slough or to enzymatically debride thick crusts (especially in neuroischemic wounds). ${ }^{75,84}$ Biodebridement with maggots has been used for many years in patients not suitable for surgical debridement and has shown some promise in removing slough and necrotic tissue while promoting granulation tissue development. ${ }^{85,86}$ Simple hydrogels or hydrocolloid dressings can provide for slow autolytic debridement of slough and dried crusts, especially in ischemic patients or those who cannot undergo surgical debridement. Regardless of the method used, effective debridement of chronic wounds is accepted as an essential component of care throughout the wound healing continuum. ${ }^{15,33,64,87}$ Nonetheless, healing can be delayed if debridement is performed too frequently and/or extensively. Development of diagnostic tools, including biomarker analysis and noninvasive imaging, is necessary to better distinguish viable from nonviable tissues in the wound and guide debridement practices. ${ }^{88}$

The importance of offloading the chronic wound cannot be overemphasized. ${ }^{89}$ In fact, when this component of wound care is neglected, the chances of a successful outcome are extremely low. When one recognizes that most wounds, especially DFUs, have excessive pressure as their proximate cause, it is quite understandable that the high pressures must be ameliorated before healing can take place. For nonplantar wounds caused by tight shoes, it is imperative that the source of offending pressures be eliminated. A number of studies and reviews have confirmed the essential role of offloading in this regard. ${ }^{90-92}$ For DFUs, the total contact cast has long been considered as the gold standard for offloading by virtue of its pressure redistribution properties as well as irremovability. Numerous additional offloading modalities have been reported for DFUs, including braces, removable cast walkers, irremovable cast walkers (often referred to as instant total contact casts), half shoes, modified surgical shoes, foot casts, and various felt or foam dressings. ${ }^{89,90,93}$ While each device has its own advantages for any given patient, almost any offloading modality is superior to no offloading for the management of DFUs.

Along the same lines, compression therapy for chronic VLUs is equally important. Since venous hypertension is at the source of these lesions, hydrostatic pressure into the skin and subcutaneous tissues underlying venous ulcers must be mitigated by external compression. ${ }^{49}$ Different modalities, such as the classic Unna's boot, threeor four-layer compression bandages, and short stretch compression bandages, have long been used in this setting. ${ }^{94}$ For ulcerated patients with significant venous insufficiency and associated chronic lymphedema, intermittent pneumatic compression pump therapy can also be recommended. While not supplanting the need for directly applied compression wraps, pump therapy will augment their effect and assist in maintaining long-term control of peripheral edema and lymphedema. ${ }^{49,95}$

Surgical offloading is a term that (as its name implies) refers to the surgical management of foot deformities causing high pressures resulting in chronic ulcerations. ${ }^{96-98}$ While not generally considered a primary treatment for most neuropathic DFUs, those that prove to be recalcitrant to standard wound bed preparation and effective offloading should be considered for surgical internal decompression. Many such procedures have been reported as effective over the last several decades. ${ }^{99-102}$ Metatarsal head osteotomies or resections, sesamoidectomies, hammertoe repair, bunionectomies, first metatarsal phalangeal joint arthroplasties, plantar exostectomies, arthrodeses, and partial calcanectomies have all been described for the management of noninfected as well as infected chronic foot ulcers. Soft tissue tendon balancing procedures, such as tenotomies, tendon transfers, and lengthening procedures, including tendo-Achilles lengthening and gastrocnemiussoleus recession, can be done as isolated procedures or in concert with osseous procedures to reduce deformities and high forefoot plantar pressures. ${ }^{103,104}$ Several authors have proposed a validated classification scheme for such operations based on the presence or absence of wounds as well as their acuity. ${ }^{97,105}$ Elective procedures are done in the absence of neuropathy, while Prophylactic operations are performed in neuropathic individuals to prevent initial ulceration over deformities or to prevent their recurrence. Curative procedures are undertaken to internally decompress chronic wounds, reduce high plantar pressures, or to remove foci of bone infection/osteomyelitis to engender final healing. Emergent operations, often including amputations, must be performed to control acute infection as limb or life-threatening measures. As has been validated, this classification trends toward an increasing need for hospitalization and frequency of amputation in the progres- 
sion from elective through emergent procedures. ${ }^{105}$ Of course, residual postoperative wounds in these patients must be treated with the same tenets of wound care as discussed above until final healing occurs. ${ }^{96}$

\section{Topical wound therapies/dressings}

While there are a myriad of topical therapies/ antimicrobials and dressings available to the clinician, very few have prospective data to support their effectiveness in promoting wound repair. Nonetheless, many therapies can indeed be useful, despite reliance on anecdotal experience. Hence, clinicians tend to use what they are accustomed to or what seems to be effective based on personal experience. Topically applied agents for wounds run the gamut from sterile saline or hydrogel to povidone-iodine solutions, cadexomer iodine, hypochlorous acid, honey, and collagenase. One topical antimicrobial agent, superoxidized solution, has recently been formally studied for efficacy in healing DFUs and was found to be effective in this regard. ${ }^{106}$ Similarly, the inexhaustible availability of dressings can make selection of the appropriate wound covering somewhat daunting. While standard cotton gauze dressings have long been considered standard of care (even in clinical trials), many other primary and secondary dressings are commercially available. Highly absorbent and moisture-retaining foam dressings, acrylics, alginates, hydrofibers, hydrocolloids, honey alginates, oxidized regenerated cellulose, micronized collagen, and many others can be considered as circumstances warrant. Many of the aforementioned products also are available with silver for control of bacterial overburden. While the use of silvercontaining products is widespread, misuse of this antibacterial element for prolonged periods is also common. While its primary use is for the reduction of bacterial colonization, there are little data to support its efficacy as a wound healing agent. ${ }^{107,108}$ It cannot be emphasized enough that standard dressings and topical therapies never supplant the need for debridement, effective offloading, and appropriate management of infection and ischemia.

\section{Advanced therapies}

All currently published guidelines and consensus reviews on the management of chronic DFUs, VLUs, and PUs support the belief that all such wounds should initially be treated with standard wound care principles as have been discussed..$^{33,49,56,64,109}$ In most cases, these basic tenets of wound care should be carried out before consideration of the use of more advanced therapies. Most wound care protocols now advocate the use of such standard measures for an initial period of 4 weeks, after which an assessment of wound area reduction should be made. While the 1999 American Diabetes Association publication was one of the first consensus documents on DFU assessment and treatment, it only mentioned that wounds failing to heal by 4 weeks were associated with worse outcomes, including amputation. ${ }^{110}$ In 2003, however, Sheehan et al. published the often quoted article supporting the ability of the 4-week healing rate to predict complete healing by 12 weeks. ${ }^{111}$ Using data from another large, multicenter randomized controlled trial (RCT), it was determined that the midpoint (median) percent wound area reduction from baseline at 4 weeks between those that healed and those that remained unhealed at 12 weeks was $53 \% .^{112}$ Those who exceeded this midpoint healed in $58 \%$ of cases by 12 weeks. In contrast, those that did not achieve $53 \%$ wound area reduction by 4 weeks only healed in $9 \%$ of cases $(p<0.001)$. Even more striking, the mean 4 -week percent change in ulcer area was $82 \%$ in healers versus $25 \%$ in the nonhealing group regardless of the treatment arm. Subsequently, the 4 -week $50 \%$ wound area reduction has been widely adopted and confirmed as a robust indicator for predicting healing at 3 months. ${ }^{33,38,64,87,109,113-115}$ Consistent with this premise, wounds failing to achieve a $50 \%$ area reduction at this time point need to be reassessed and subsequently considered for advanced therapies in the absence of underlying disease or nonadherence to prescribed basic treatment. ${ }^{33,64}$ Figure 3 illustrates a fairly common algorithm for DFU treatment incorporating these principles. Figure 4 similarly illustrates an algorithm for VLU treatment.

Once it is determined that the patient might benefit from an advanced therapeutic agent, there are a number of options currently available. ${ }^{6,116-118}$ While there have been several key RCTs published on advanced wound care agents for chronic wounds, most such products do not have the benefit of highlevel evidence or even nonrandomized prospective studies to attest to their efficacy. Advanced wound therapies can best be discussed by broadly categorizing them according to their specific technologies or engineering, tissue types, cell types, or protein content (i.e., growth factors). Even this scheme will not capture the myriad products, proteins, and molecules that have undergone trials and failed to demonstrate superiority over standard of care treatment. While not exhaustive, Table 3 provides a listing of the more common wound care technologies currently in use in the United States and abroad. 


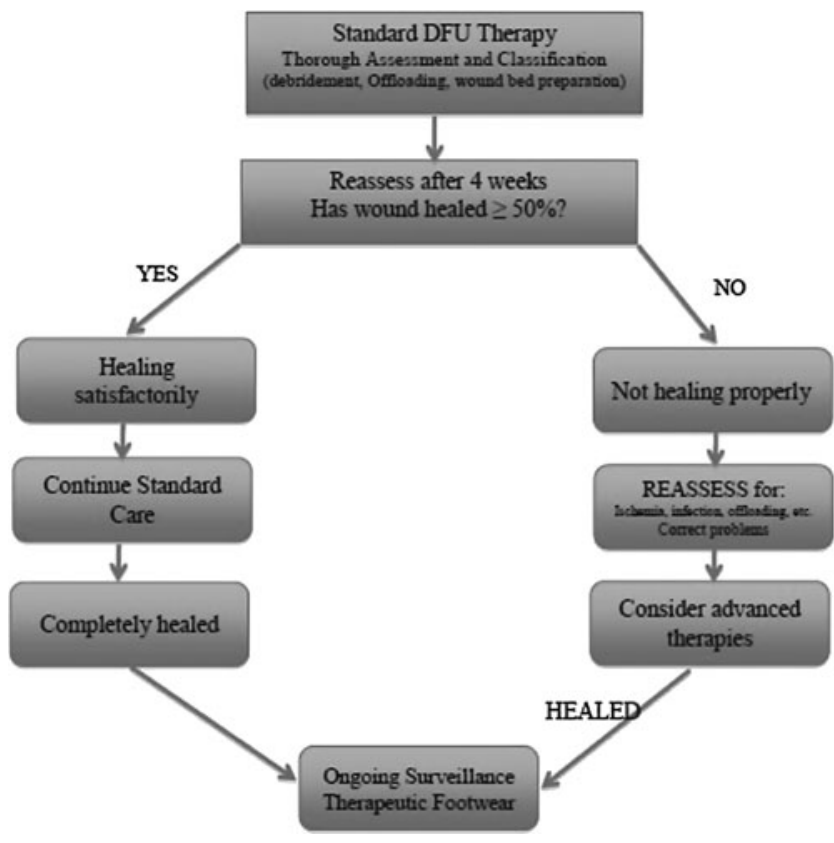

Figure 3. Simplified algorithm for diabetic foot ulcer (DFU) treatment.

\section{Negative pressure wound therapy}

Since its introduction in the mid 1990s, negative pressure therapy has assumed a major role in the management of traumatic, acute, and chronic wounds, as well as for stabilizing skin grafts, flaps, and surgical incisions. ${ }^{119-123}$ Since the early studies of Morykwas et al. and Argenta and Morykwas that demonstrated the numerous attributes of NPWT, a very large body of evidence has been published supporting the clinical efficacy of this

\section{Simplified VLU Algorithm}

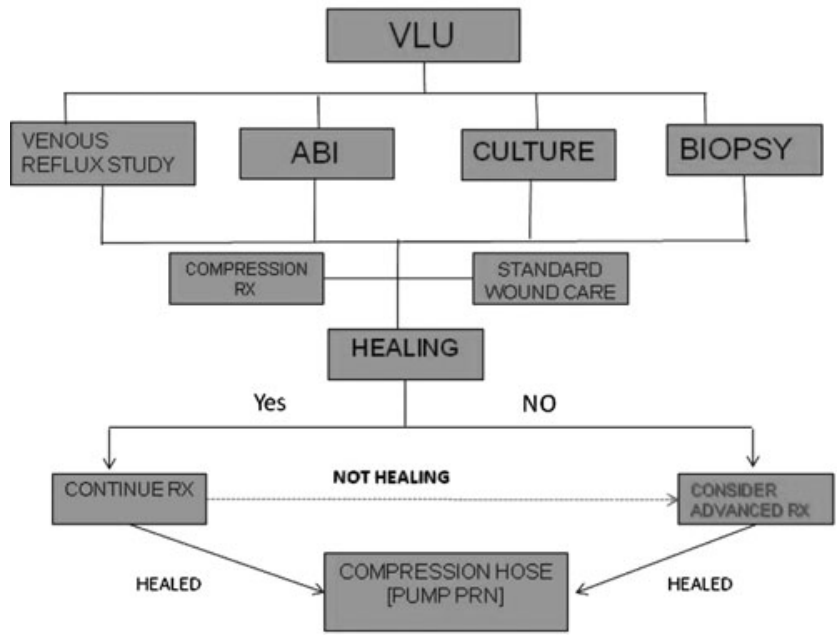

Figure 4. Simplified algorithm for venous leg ulcer (VLU) treatment. $A B I$, ankle-brachial indices.
Table 3. Wound care technologies

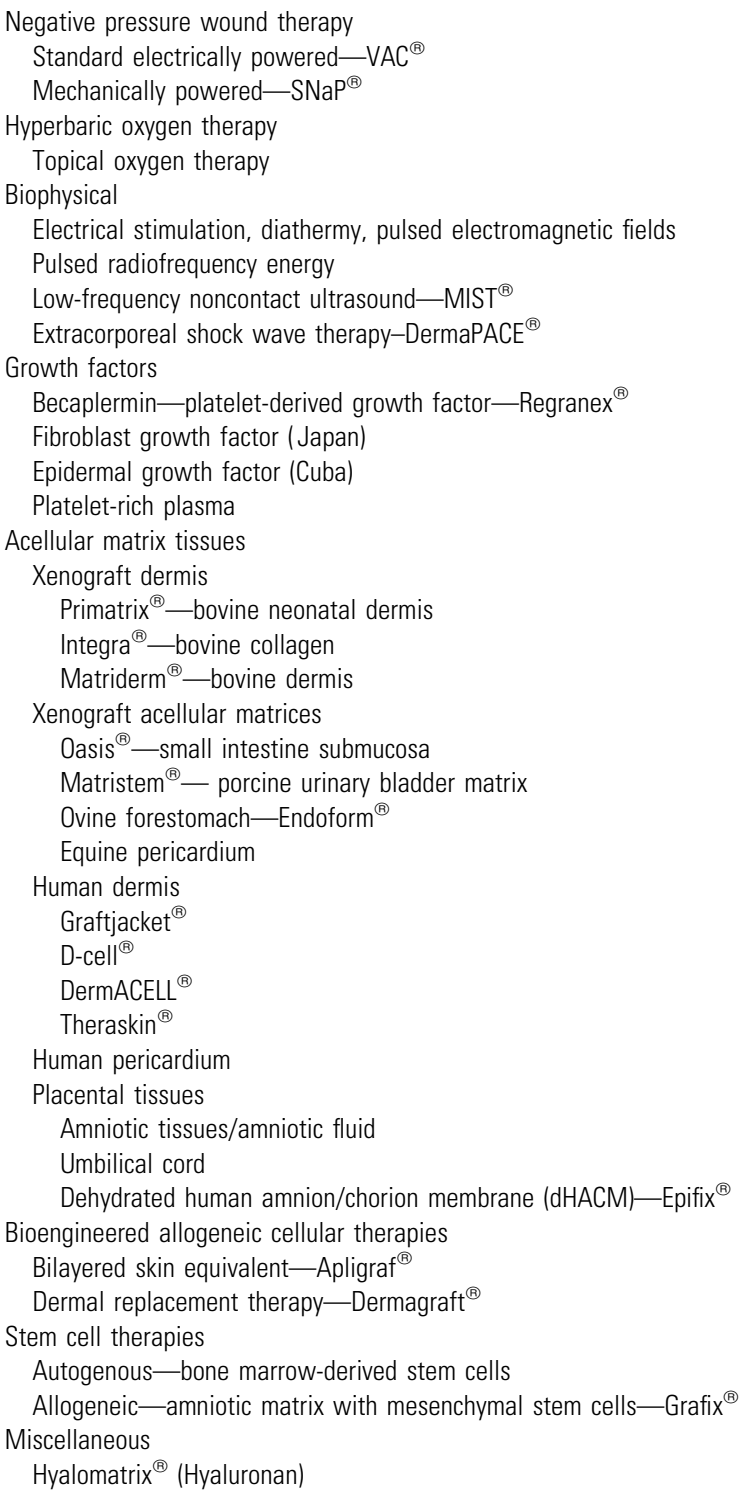

very important biophysical modality. ${ }^{121,124-129}$ Clinical trials have been conducted in the ensuing years that have proven the superiority of NPWT over standard therapy for managing open amputation wounds, DFUs, VLUs, and other wounds. ${ }^{130-132}$ As an adjunct to standard chronic wound care, NPWT very efficiently manages wound drainage and can provide expedited granulation tissue development, wound area contraction/reduction, preparation for delayed closure or grafting, or primary healing. ${ }^{133,134}$ NPWT is also quite useful as a bolster to enhance the incorporation of skin grafts onto recipient wound beds. ${ }^{135}$ Application techniques are important, however, since inappropriate placement of tubing can potentially cause skin pressure lesions. Therefore, a 
bridging method that provides for suction tubing placement away from plantar surfaces has become an important application technique. More recently, these electrically powered devices have added the ability to instill saline or other antimicrobial agents to assist in the cleansing of the wounds concurrent with providing the aforementioned benefits of NPWT. ${ }^{128,136-138}$ A mechanically powered, ultralight, and portable NPWT device has also been introduced in recent years. ${ }^{135,139,140}$ Two articles comparing this device with the traditional electrically powered device in a prospective RCT have shown equivalent DFU healing outcomes with faster application times and a high degree of patient satisfaction. ${ }^{141,142}$ Clinicians have also combined NPWT with other advanced therapies such as acellular and cellular matrices. ${ }^{143}$ Such multimodal therapies can be administered concurrently or sequentially as wound characteristics change to provide the optimum therapy for any given wound.

\section{Hyperbaric oxygen therapy}

HBOT has been advocated as being beneficial for a wide variety of chronic wounds for over two decades. ${ }^{144-150}$ While there are numerous retrospective and prospective studies, case series, cohort studies, and several trials indicating the efficacy of HBOT for the treatment of DFUs and VLUs, the general quality of these studies is not robust since inclusion criteria and outcomes are highly variable. ${ }^{6,144,145,150-156}$ While the recent Cochrane review in 2012 indicated significant short-term improvement for healing DFUs over controls at 6 weeks (relative risk [RR] 5.20; $p=0.02$ ), this benefit was not evident at 1 year or longer. ${ }^{157}$ While there was a suggestion that HBOT may decrease the major amputation rate in DFU patients, pooled analysis of the data did not yield a significant estimate for this association (RR $0.36,95 \%$ confidence interval 0.11 to $1.18, p=0.08$ ). The $2010 \mathrm{RCT}$ by Londahl et al. reported favorable outcomes at 1 year for HBOT in those patients with Wagner grade 2,3 , or 4 DFUs failing prior standard interventions for $>3$ months ( $52 \%$ vs. $29 \%, p=0.03){ }^{69}$ Unfortunately, the heterogeneity of the patients and time to reported outcomes (9 months or 1 year) make comparisons with other DFU trials difficult. A more recent review of HBOT in a large observational cohort study by Margolis found that the use of HBOT neither improved the likelihood that a wound would heal nor prevented amputation in patients with adequate lower limb arterial perfusion. ${ }^{158}$ This review and the aforementioned Cochrane review both called for a reevaluation of
HBOT with rigorously designed adequately powered trials to assess efficacy in healing chronic wounds.

Since the very poorly conducted 14-day study by Leslie et al. in 1988, the use of topical wound oxygen for DFUs and VLUs has been considered as highly controversial, especially by advocates of HBOT. ${ }^{71}$ The lack of a formal study in this regard has been offset by several reviews, case series, and experimental studies on the effect of topically administered oxygen at the wound surface that seem to indicate a benefit in promoting wound repair. ${ }^{154,159-169}$ While several RCTs with different devices have been ongoing, there have been no publications to date comparing 12 -week healing rates with those of standard care.

\section{Biophysical modalities}

Electrical stimulation has been the most studied biophysical device for healing chronic wounds to date, primarily utilized by physical therapists and physiatrists. ${ }^{170-173}$ An abundance of studies advocates the beneficial healing effect of electrical stimulation at various modes and frequencies for a variety of chronic wounds. ${ }^{174-177}$ Other nonthermal forms of electromagnetic energy have also been used for wound healing, including pulsed radiofrequency energy (PRFE), pulsed shortwave diathermy, and pulsed electromagnetic fields. ${ }^{173,178,179}$ One in vitro study of PRFE effects on cultured dermal fibroblasts and keratinocytes found this electromagnetic field to upregulate expression of a variety of genes involved in modulating the inflammatory stage of wound healing. ${ }^{180}$ In general, by interacting with endogenous bioelectric currents, electromagnetic fields indirectly upregulate the production of nitric oxide and multiple growth factors, resulting in cellular mobilization, angiogenesis, and expedited wound repair. ${ }^{173,176}$

Ultrasound, most frequently used for diagnostic and musculoskeletal therapy purposes, has also assumed a role in wound management. Several lower frequency devices are currently available for debridement that use the delivery of sound waves to generate cavitation at the wound bed. ${ }^{173,181}$ Wounds with thick fibrinous slough and necrosis can thereby be very aggressively debrided with low-frequency ultrasound (LFU) devices, although trials to show improved healing rates have not been conclusive. ${ }^{181-183}$ Noncontact LFU using a saline droplet carrier to the wound surface has been proposed as another LFU device that can improve healing rates of chronic ulcers, including those complicated by ischemia. ${ }^{170,184-188}$ While this noncontact LFU modality can assist with wound 
bed preparation, it cannot aggressively debride wounds as well as the aforementioned units. Several retrospective observational studies and one low quality RCT suggested improvements in healing rates over standard of care comparators, but confirmatory prospective studies have not been forthcoming. ${ }^{84-186,188}$

Extracorporeal shock wave therapy (ESWT) has been used for a number of years for a variety of musculoskeletal conditions and has recently been adapted for the treatment of cutaneous wounds. ESWT is defined as a series of high-energy acoustic pulses delivered to tissues by electrohydraulic, electromagnetic, and piezoelectric sources. ${ }^{189}$ The pressure pulses generated promote a cascade of cytokine and growth factor upregulation leading to enhanced neovascularization, anti-inflammatory response, and tissue regeneration. ${ }^{190,191}$ Several recent reviews and one study comparing ESWT with HBOT on DFU healing support its potential role in expediting wound repair. ${ }^{189-191}$ Nonetheless, RCTs are still required to evaluate the clinical efficacy of this modality in healing chronic wounds of different etiologies.

\section{Biological and bioengineered therapies}

Concurrent with the explosive growth of negative pressure therapies and HBOT for the management of chronic wounds in the last two decades, there has been an enormous amount of research and interest in advanced biological therapies. In this regard, biological therapies refer to tissuebased treatments (acellular and cellular), autologous platelet-rich plasma (PRP), as well as recombinant human growth factor therapies. While the latter can be considered as a category unto themselves due to the enormous amount of preclinical research on cytokine and growth factor-mediated wound repair, there are currently only several such therapies commercially available to cliniciansrecombinant human platelet-derived growth factor (rhPDGF), fibroblast growth factor (rhFGF), and epidermal growth factor (rhEGF). Numerous other growth factors have been isolated and investigated, such as vascular endothelial growth factor (VEGF), keratinocyte growth factor-2, TGF- $\beta$, and granulocyte-macrophage colony-stimulating factor, but these currently are not approved for use in wound care. ${ }^{192}$

Platelet-rich plasma and growth factors. The clinical interest in growth factor therapies over the last 25 years actually stemmed from the early work of Knighton et al. on autologous PRP and the cascade of growth factors released from activated platelets during the centrifugation of whole blood. ${ }^{193-195}$ Several small trials and retrospective reviews have affirmed the potential efficacy of topically applied, activated, autologous platelet supernatants for expedited healing of chronic lower extremity wounds. ${ }^{196-199}$ After recognizing the potential benefit of topically applied PDGF to chronic wounds, becaplermin gel (rhPDGF) was studied in the setting of chronic neuropathic DFUs and became the first commercially available advanced therapy for the management of these difficult wounds (and the only growth factor approved for use in the United States). ${ }^{200-202}$ In the 20-week phase III clinical trial by Wieman leading to its approval, topically applied rhPDGF gel was found to significantly increase the incidence of complete wound closure by $43 \%$ and decrease the time to healing by $32 \%$ over placebo-controlled standard wound care. ${ }^{203}$ The efficacy of the single topically applied growth factor was corroborated as being beneficial to the healing of chronic nonischemic foot ulcers when combined with good standard wound care in several other studies pooling data from multiple sources. ${ }^{200,202,204}$

rhEGF is perhaps the best studied growth factor for cutaneous ulcers and wounds, but is not available in the United States. ${ }^{205-212}$ Applied as a topical cream, or more commonly, by intralesional injections, EGF has been found also to expedite the healing of a variety of types of cutaneous wounds. Several small trials have been published from Asia and Cuba attesting to the healing benefits of EGF compared with controls. ${ }^{207-209,213}$ However, the heterogeneity of wounds, applications, patient management protocols, and outcomes has not lead to clinical trials in the United States nor to widespread global adoption of this therapy.

FGF has been studied primarily in Asia for a variety of chronic wounds, including DFUs, VLUs, and PUs, and is approved in Japan for this use. ${ }^{214-218}$ FGF, considered a potent angiogenic growth factor, also has an isoform (FGF-10) commonly known as keratinocyte growth factor-2 or repifermin. ${ }^{192,217}$ This agent has been studied in the United States for chronic VLUs as a topical spray. Repifermin was shown to accelerate wound healing with significantly more patients achieving $75 \%$ wound closure with repifermin than with placebo after 12 weeks. The treatment effect appeared more marked for a subgroup of patients with initial wound areas $\leq 15 \mathrm{~cm}^{2}$ and wound ages of $\leq 18$ months. ${ }^{217} \mathrm{Un}$ fortunately, there were no significant differences between the study and control groups for the primary outcome (healing at 12 weeks), likely due to methodological issues in the study protocol. 
Neither repifermin nor FGF has been approved in the United States for wound management.

Acellular therapies. The most common types of advanced biological therapies for chronic wounds can generally be classified as acellular therapiesthose dermal, amniotic, or collagen-based tissues (human or animal) that have been decellularized during their processing. Often referred to as acellular and/or ECMs, these biological products serve as substrates into which cells can migrate and initiate angiogenesis, thereby promoting granulation tissue development and tissue regeneration. ${ }^{116}$ Once considered only as inert structural collagen tissue providing a scaffold for cellular ingrowth, ECMs are now known to play an active part in tissue regeneration through a dynamic interaction with growth factors and host cells. ${ }^{219-221}$ ECMs contain not only structural collagen but also glycosaminoglycans (including hyaluronan), proteoglycans, and glycoproteins-all essential components to replace the defective ECM of injured tissues. ${ }^{222,223}$ Currently available nonhuman ECM products with clinical data to support their efficacy include porcine-derived small intestinal submucosa, porcine urinary bladder matrix, bovine dermis, equine pericardium, and sheep (ovine) bladder. ${ }^{224-233}$ Another matrix dressing (Hyalomatrix $^{\circledR}$; Anika Therapeutics, Inc., Bedford, MA) comprising primarily hyaluronan, one of the main constituents of ECM, has also been studied in Europe as a dermal substitute for use in burns, VLUs, and DFUs. ${ }^{234-237}$ Integra $^{\circledR}$ bilayer wound matrix (Integra LifeSciences, Plainsboro, NJ) is a dermal regeneration template in this category (bovine collagen, glycosaminoglycans, and silicone layer) that has primarily been used in burns for a number of years, but is being more frequently used in lower extremity chronic wounds and foot ulcers. $^{238,239}$ Although there are few published prospective studies to support their efficacy, most of these products are commercially available in the United States at relatively low cost and are approved for use in multiple chronic wound types.

Human dermal allografts have become increasingly popular in recent years for augmenting tissue regeneration in chronic lower extremity wounds and have been formally studied in DFUs and VLUs. These are defined by the Food and Drug Administration as human cellular and tissue-based products. The allografts are harvested from screened donors, and each is prepared with proprietary processes to decellularize and cryopreserve the dermis while maintaining the natural structure of the collagen and ECM. ${ }^{240-245}$ As with the aforementioned ECM products, the dermal matrices serve as scaffolds for cellular repopulation and angiogenesis, with varying degrees of incorporation into the recipient wound bed. ${ }^{246,247}$ One of these cryopreserved dermal allografts, referred to as a human skin allograft, claims that both the extracellular and cellular components are preserved during the minimal processing. ${ }^{242,243}$ Two of the available dermal regenerative matrices have successfully undergone small RCTs (Graftjacket ${ }^{\circledR}$; KCI, San Antonio, TX and TheraSkin ${ }^{\circledR}$; Soluble Systems, Newport News, VA), while a third is currently undergoing a clinical trial for DFUs (dCell ${ }^{\circledR}$; Tissue Regenix, San Antonio, TX). ${ }^{240,243}$ Available data suggest that acellular dermal matrices, in addition to basic wound care principles, may provide an effective technique for tissue regeneration in deep and cutaneous extremity wounds. ${ }^{221,246}$

Amniotic membranes (AMs) and umbilical cord tissues have been used for many years for corneal ulcers and were actually the earliest reported biomaterials used for wound repair. In recent years, there has been a greatly expanded interest in these tissues for chronic wounds, likely due to the wide availability of placental tissues after cesarean deliveries. Due to their rich cellular content in the native state, AMs contain a number of cytokines and growth factors bound to the ECM after decellularization and preparation that remain available to augment angiogenesis and tissue repair when implanted into chronic wounds. ${ }^{248-251}$ AMs are available in the cryopreserved state or as dehydrated products for direct implantation. ${ }^{250,252,253}$ Several products are also available in a micronized formulation that can be applied topically or hydrated for injection into wounds or other inflamed tissues (tendonitis, plantar fasciitis, etc.) to augment healing. ${ }^{254}$ Amniotic fluid with granulized amniotic matrix is also available for the management of chronic wounds. ${ }^{255}$ While several retrospective and prospective studies have supported the benefit of amniotic matrix products for chronic wound repair, the only published randomized and comparative studies to date have utilized the dehydrated human amnion/chorion membrane (dHACM) ${ }^{255-262}$ In the initial small RCT of just $25 \mathrm{DFU}$ patients in a single center, Zelen et al. reported a $92 \%$ healing rate after 6 weeks in the dHACM (Epifix ${ }^{\circledR}$; Mimedix Group, Marietta, GA) group compared with $8 \%$ in the standard of care group $(p<0.001){ }^{261}$ In a crossover study of unhealed patients in the control arm of the RCT, $91 \%$ healed by 12 weeks with biweekly dHCAM application. ${ }^{259}$ Subsequent studies ascertained that weekly applications of this allograft provided more rapid healing of DFUs than biweekly application and that healing frequency with the 
amnion/chorion product was significantly higher than patients assigned to either a bilayered skin substitute or to standard of care treatment in another comparative trial. ${ }^{260,262}$ Many of the aforementioned studies, however, were sponsored by a single company with a single product and the same investigative group. Since a number of other AM products are now commercially available, further studies should be forthcoming to determine if there is a distinction between different amniotic matrices pertaining to efficacy in wound repair.

Bioengineered cellular therapies. For more than a decade, two allogeneic bioengineered skin replacement therapies utilizing neonatal expanded cells have been available in the United States market to address chronic wounds. Both products underwent formal, controlled clinical trials before their approval for use. The first cellular product (Apligraf $^{\circledR}$; Organogenesis, Canton, MA) is a bilayered construct consisting of a bovine collagen matrix seeded with living human neonatal fibroblasts and a neonatal keratinocyte neoepidermis. It is approved for both chronic VLUs as well as DFUs. This living skin equivalent not only addresses the deficient ECM of chronic wounds by adding a collagen matrix but also introduces immune-privileged living cells that proliferate and actively synthesize growth factors, cytokines, and ECM products. ${ }^{263-265}$ In the pivotal, multicenter, 12-week clinical trial, patients randomized to the Apligraf group achieved complete healing in $56 \%$ of cases compared with $38 \%$ in the control group $(p=0.0042) .{ }^{266}$ With an average of four applications, the bilayered skin equivalent also healed the chronic DFUs significantly faster than those patients treated with standard care (65 vs. 90 days, $p=0.0026$ ). Other subsequent investigations found similar efficacy of this bioengineered product for healing chronic diabetic foot wounds as well as VLUs. ${ }^{267,268}$

Dermagraft $^{\circledR}$ (Organogenesis, Canton, MA) is a human fibroblast-derived dermal substitute (HFDS) comprising a cryopreserved, absorbable, threedimensional polyglactin mesh substrate seeded with living neonatal dermal fibroblasts. ${ }^{269}$ Similar to the bilayered skin replacement, these cells secrete a host of growth factors, cytokines, matrix proteins, and glycosaminoglycans that induce tissue regeneration through the development of granulation tissue and ingrowth of host fibroblasts and keratinocytes. ${ }^{270,271}$ This dermal substitute was proven effective in healing chronic DFUs in the pivotal trial by Marston et al. in $2003 .^{272}$ In this multicenter clinical trial, those patients assigned to the HFDS group healed significantly faster after
12 weeks compared with the standard wound care group (30\% vs. $18.3 \%, p=0.023$ ). Despite the ostensibly low overall healing rate, the study group achieved a $64 \%$ increased healing compared with the standard care group. This was a greater margin of effect than reported in any previous trial. Despite the failure to achieve superiority in its primary outcome of complete healing in a large VLU trial, significant differences in complete healing were achieved for a subgroup of ulcers $\leq 12$ months in duration $(p=0.029){ }^{273}$ Other authors have reported success with the dermal substitute in a variety of lower extremity wounds, often used in concert with other wound healing modalities. ${ }^{274-}$ 277 A recent study investigated the incidence of amputations and bone resections within the two arms of the DFU pivotal trial and found a decreased incidence of these complications in the HFDS group, likely related to a lower incidence of infection and faster healing in the investigational treatment group. ${ }^{278}$

Stem cell therapies. Perhaps the most recent advancements for wound care therapies are that of stem cell therapies, primarily bone marrow derived, and most recently, placental-derived stem cells. Both sources are considered as adult stem cells, and the cell lineage of interest are the MSCs. Briefly, MSCs are multipotent progenitor cells that can directly differentiate into mesenchymal tissues, such as bone, tendon, and cartilage. Their ability to affect cutaneous repair, however, is through an indirect paracrine function (trophic activity), whereby they synthesize essential growth factors and cytokines that affect cell migration, proliferation, and metabolic activity of host cells and tissues. ${ }^{30,279,280}$ In this manner, MSCs play an active role in the inflammatory, proliferative, and remodeling phases of wound repair. ${ }^{281}$ Interestingly, MSCs can respond to the host environment by upregulating anti-inflammatory cytokines in the presence of inflammation and respond to hypoxic environments by upregulating the release of VEGF to induce angiogenesis. During the remodeling phase, MSCs produce growth factors, such as TGF- $\beta 3$, to limit excessive scarring as well as modulate the balance between matrix metalloproteinases and tissue inhibitors of metalloproteinases while regulating collagen deposition. Important for allogeneic implantation, MSCs are characterized as being immune privileged since they lack cell surface antigens that would typically engender a foreign body reaction. ${ }^{281}$

Bone marrow-derived stem cells (BMSCs) have been of interest for some time now and studies have 
indicated their ability to augment repair or regeneration of numerous tissues, including cardiac, bone, cartilage, blood vessels, and skin. ${ }^{30,282,283}$ Although much interest has focused on orthopedic and critical limb ischemia applications, BMSCs are increasingly being studied for use in enhancing chronic wound and cutaneous repair. ${ }^{18,284-291}$ Several articles and clinical studies have specifically focused on DFU management. ${ }^{292-294}$ One of the earlier studies by Yamaguchi et al. took a novel approach by decorticating exposed bone at the base of the ulcer to locally release bone marrow cells directly into the wound. ${ }^{290}$ This was followed several weeks later by application of autologous epidermal grafts, resulting in significantly improved healing compared with standard wound care $(p<0.0001)$. In another small case series by Rogers et al., BMSCs were harvested from the ipsilateral distal tibial metaphysis, and the aspirate was applied topically or by peripheral injection under the debrided wounds with good results. ${ }^{287}$ Large randomized studies have not yet been published comparing wounds treated with BMSCs with standard care. Another issue for consideration in such trials will be standardizing methods for obtaining and processing the marrow aspirates, as well as potential complications associated with this surgical procedure.

Placental tissues-including the umbilical cord, the amnion, and the chorion-are a rich source of MSCs and are readily available without the ethical concerns of embryonic stem cells. ${ }^{281,292}$ Furthermore, the MSCs in these tissues do not suffer from the age-related effects nor decreased cell counts as found in MSCs harvested from adult patients with comorbid diseases. ${ }^{279,293,295}$ Placental-derived MSCs show minimal differences from those obtained from different sites, and yet retain all of the metabolic, paracrine, and immunomodulative properties previously described while maintaining their immune-privileged status. ${ }^{281}$ Traditionally, placental or amniotic tissues used for wound repair were prepared from fresh cesarean section donors. One small modern study investigated the efficacy of fresh AM on the healing of chronic VLUs and found a positive effect on pain reduction and a significant clinical response (20\% completely healed) within the 3 -month follow-up period. ${ }^{257}$ Overcoming the difficulties of fresh transplantation, a new cryopreserved AM product (Grafix ${ }^{\circledR}$; Osiris Therapeutics, Inc., Columbia, MD) has become commercially available in recent years. This human MSC-rich wound matrix contains viable cells, including fibroblasts and epithelial cells, in addition to MSCs and a natural ECM. ${ }^{281}$ In a single-center retrospective study of 67 chronic lower extremity wounds, including VLUs and DFUs, this viable wound matrix in association with good standard wound care was found to close $76.1 \%$ of wounds at 12 weeks with a mean time to healing of 5.8 weeks. ${ }^{296}$ A subsequent 12 -week RCT comparing the efficacy of Grafix to standard of care for the healing of DFUs was published in $2014 .{ }^{297} \mathrm{In}$ this pivotal trial where the primary outcome was complete wound healing at 12 weeks, those patients assigned to weekly applications of the viable human matrix healed significantly more DFUs than those in the control group ( $62 \%$ vs. $21 \%, p=0.0001$ ). The median time to healing was also significantly faster in the study group ( 42 vs. 69.5 days, $p=0.019$ ). Of particular interest, those unhealed patients in the control group were allowed to crossover to receive up to 12 weeks of viable stem cell matrix therapy. The probability for closure in these patients was $67.8 \%$ with a mean time to closure of 42 days. ${ }^{297}$ The results of this study represent a margin of effect between active and control groups of $191 \%$, higher than any other published study to date.

\section{SUMMARY}

Complex wounds represent a major challenge for the clinician and wound care specialist. Despite all 
the recent advances in wound care therapies and our understanding of the pathophysiology underlying chronic wounds, nothing can supplant the need for adhering to the basic tenets of wound care: thorough assessment with medical and nutritional optimization, debridement (including surgery), offloading (or compression), management of ischemia, management of infection, and appropriate wound bed preparation. Following these principles and established wound care guidelines should often lead to satisfactory outcomes. In addition, the rational use of advanced wound care therapies is encouraged when wounds do not respond sufficiently to good standard care after 4 weeks or sooner as circumstances dictate. In most cases, selection of advanced therapies should be based on the evidence available to help facilitate their most appropriate use.

\section{ACKNOWLEDGMENT AND FUNDING SOURCES}

The authors thank Alla Danilkovitch, $\mathrm{PhD}$, for her review and thoughtful suggestions. No competing financial interests exist.

\section{AUTHOR DISCLOSURE AND GHOSTWRITING}

The opinions expressed are those of the authors and do not represent those of the Department of Veterans Affairs or the United States Government. No ghostwriters were used to write this article.

\section{ABOUT THE AUTHORS}

Robert G. Frykberg, DPM, MPH, received his Doctor of Podiatric Medicine degree from the Ca- lifornia College of Podiatric Medicine in 1976 before completing his residency in podiatric surgery at the New England Deaconess Hospital/Harvard Medical School, Boston, in 1978. In 1994, he received his Master of Public Health degree from the Harvard School of Public Health with a concentration in quantitative methods. He was an attending physician at the Deaconess Hospital for 21 years before accepting a position as the Dean for Clinical Affairs in the College of Podiatric Medicine at Des Moines University in 1999. Dr. Frykberg currently holds the position of Chief of the Podiatry section and Podiatric Residency Director at the Carl T. Hayden Veterans Affairs Medical Center in Phoenix, Arizona, and is an Adjunct Professor, Midwestern University Program in Podiatric Medicine. Dr. Frykberg's practice is devoted primarily to patients with high-risk foot problems. His research and writing interests are in diabetic foot disorders, including ulcers, infections, and the Charcot foot, VLUs, peripheral arterial disease, and wound care. He has written numerous peer-reviewed articles and text chapters and has published several textbooks on diabetic foot disorders. He is the former Chair of the Foot Care Council of the American Diabetes Association and a Past President of the American College of Foot and Ankle Surgeons. He was the 2011 recipient of the prestigious Roger Pecoraro Award from the Foot Care Council of the American Diabetes Association. Jaminelli Banks, DPM, is a research fellow and clinical research coordinator at the Phoenix VA Medical Center. She attended Temple University School of Podiatric Medicine in Philadelphia, PA. Her previous research affiliations include Temple University Gait Lab, National Institutes of Health, and Lovelace Respiratory Research Institute.

\section{REFERENCES}

1. Brownrigg JR, Apelqvist J, Bakker K, Schaper NC, Hinchliffe RJ. Evidence-based management of PAD \& the diabetic foot. Eur J Vasc Endovasc Surg 2013;45:673-681.

2. Richmond NA, Maderal AD, Vivas AC. Evidence-based management of common chronic lower extremity ulcers. Dermatol Ther 2013;26: 187-196.

3. Canadian Agency for Drugs and Technologies in Health. Optimal Care of Chronic, Non-Healing, Lower Extremity Wounds: A Review of Clinical Evidence and Guidelines. Ottawa, ON, Canada, 2013.
4. Rice JB, Desai U, Cummings AK, Birnbaum HG, Skornicki M, Parsons NB. Burden of diabetic foot ulcers for medicare and private insurers. Diabetes Care 2014;37:651-658.

5. Shankaran V, Brooks M, Mostow E. Advanced therapies for chronic wounds: NPWT, engineered skin, growth factors, extracellular matrices. Dermatol Ther 2013;26:215-221.

6. Nunan R, Harding KG, Martin P. Clinical challenges of chronic wounds: searching for an optimal animal model to recapitulate their complexity. Dis Model Mech 2014;7:1205-1213.
7. Woo K, Ayello EA, Sibbald RG. The edge effect: current therapeutic options to advance the wound edge. Adv Skin Wound Care 2007;20:99117; quiz 118-119.

8. Stojadinovic A, Carlson JW, Schultz GS, Davis TA, Elster EA. Topical advances in wound care. Gynecol Oncol 2008;111:S70-\$80.

9. Attinger CE, Janis JE, Steinberg J, Schwartz J, Al-Attar A, Couch K. Clinical approach to wounds: debridement and wound bed preparation including the use of dressings and woundhealing adjuvants. Plast Reconstr Surg 2006;117: 72S-109S. 
10. Demidova-Rice TN, Salomatina EV, Yaroslavsky AN, Herman IM, Hamblin MR. Low-level light stimulates excisional wound healing in mice. Lasers Surg Med 2007;39:706-715.

11. Edmonds M. Body of knowledge around the diabetic foot and limb salvage. J Cardiovasc Surg (Torino) 2012;53:605-616.

12. Eming SA, Martin P, Tomic-Canic M. Wound repair and regeneration: mechanisms, signaling, and translation. Sci TransI Med 2014;6:265sr266.

13. Sun BK, Siprashvili Z, Khavari PA. Advances in skin grafting and treatment of cutaneous wounds. Science 2014;346:941-945.

14. Falanga V. Wound healing and its impairment in the diabetic foot. Lancet 2005;366:1736-1743.

15. Schultz GS, Sibbald RG, Falanga V, et al. Wound bed preparation: a systematic approach to wound management. Wound Repair Regen 2003;11 Suppl 1:S1-S28.

16. McCarty SM, Percival SL. Proteases and delayed wound healing. Adv Wound Care 2013;2:438-447.

17. Schreml S, Szeimies RM, Prantl L, Karrer S, Landthaler M, Babilas P. Oxygen in acute and chronic wound healing. $\mathrm{Br} J$ Dermatol 2010;163:257-268.

18. Dhall S, Do DC, Garcia M, et al. Generating and reversing chronic wounds in diabetic mice by manipulating wound redox parameters. J Diabetes Res 2014:2014:562625.

19. Stanley A, Osler T. Senescence and the healing rates of venous ulcers. J Vasc Surg 2001;33:1206-1211.

20. Lobmann R, Ambrosch A, Schultz G, Waldmann K, Schiweck S, Lehnert H. Expression of matrixmetalloproteinases and their inhibitors in the wounds of diabetic and non-diabetic patients. Diabetologia 2002;45:1011-1016.

21. Tsourdi $E$, Barthel $A$, Rietzsch $H$, Reichel $A$ Bornstein SR. Current aspects in the pathophysiology and treatment of chronic wounds in diabetes mellitus. Biomed Res Int 2013;2013:385641.

22. Bourguignon LY. Matrix hyaluronan-activated CD44 signaling promotes keratinocyte activities and improves abnormal epidermal functions. Am J Pathol 2014;184:1912-1919.

23. Cook H, Davies KJ, Harding KG, Thomas DW Defective extracellular matrix reorganization by chronic wound fibroblasts is associated with alterations in TIMP-1, TIMP-2, and MMP-2 activity. J Invest Dermatol 2000;115:225-233.

24. Telgenhoff D, Shroot B. Cellular senescence mechanisms in chronic wound healing. Cell Death Differ 2005;12:695-698.

25. Wall IB, Moseley R, Baird DM, et al. Fibroblast dysfunction is a key factor in the non-healing of chronic venous leg ulcers. J Invest Dermatol 2008;128:2526-2540

26. Bitar MS. The GSK-3beta/Fyn/Nrf2 pathway in fibroblasts and wounds of type 2 diabetes: on the road to an evidence-based therapy of nonhealing wounds. Adipocyte 2012;1:161-163.
27. Ennis WJ, Sui A, Bartholomew A. Stem cells and healing: impact on inflammation. Adv Wound Care 2013;2:369-378.

28. Cianfarani F, Toietta G, Di Rocco G, Cesareo E, Zambruno G, Odorisio T. Diabetes impairs adipose tissue-derived stem cell function and efficiency in promoting wound healing. Wound Repair Regen 2013;21:545-553.

29. Rodriguez-Menocal L, Salgado M, Ford D, Van Badiavas E. Stimulation of skin and wound fibroblast migration by mesenchymal stem cells derived from normal donors and chronic wound patients. Stem Cells Transl Med 2012;1:221-229

30. Shin L, Peterson DA. Human mesenchymal stem cell grafts enhance normal and impaired wound healing by recruiting existing endogenous tissue stem/progenitor cells. Stem Cells Transl Med 2013;2:33-42

31. Lazarus GS, Cooper DM, Knighton DR, et al. Definitions and guidelines for assessment of wounds and evaluation of healing. Arch Dermatol 1994;130:489-493.

32. Chow 0 , Barbul A. Immunonutrition: role in wound healing and tissue regeneration. Adv Wound Care 2014;3:46-53.

33. Frykberg RG, Zgonis T, Armstrong DG, et al. Diabetic foot disorders. A clinical practice guideline (2006 revision). J Foot Ankle Surg 2006;45:S1-S66.

34. Grayson ML, Gibbons GW, Balogh K, Levin E, Karchmer AW. Probing to bone in infected pedal ulcers. A clinical sign of underlying osteomyelitis in diabetic patients. JAMA 1995;273:721-723.

35. Alvaro-Afonso FJ, Lazaro-Martinez JL, AragonSanchez J, Garcia-Morales E, Garcia-Alvarez Y, Molines-Barroso RJ. Inter-observer reproducibility of diagnosis of diabetic foot osteomyelitis based on a combination of probe-to-bone test and simple radiography. Diabetes Res Clin Pract 2014;105:e3-e5.

36. Abbott CA, Vileikyte L, Williamson S, Carrington AL, Boulton AJ. Multicenter study of the incidence of and predictive risk factors for diabetic neuropathic foot ulceration. Diabetes Care 1998;21:1071-1075.

37. Young MJ, Breddy JL, Veves A, Boulton AJ. The prediction of diabetic neuropathic foot ulceration using vibration perception thresholds. A prospective study. Diabetes Care 1994;17:557-560.

38. Boulton AJ, Kirsner RS, Vileikyte L. Clinical practice. Neuropathic diabetic foot ulcers. N Engl J Med 2004;351:48-55

39. American Diabetes Association. Peripheral arterial disease in people with diabetes. Diabetes Care 2003;26:3333-3341.

40. Boulton AJ, Armstrong DG, Albert SF, et al Comprehensive foot examination and risk assessment: a report of the task force of the foot care interest group of the American Diabetes Association, with endorsement by the American Association of Clinical Endocrinologists. Diabetes Care 2008;31:1679-1685.
41. Gibbons GW, Wheelock FC, Jr., Siembieda C, Hoar CS, Jr., Rowbotham JL, Persson AB. Noninvasive prediction of amputation level in diabetic patients. Arch Surg 1979;114:1253-1257.

42. Kalani M, Brismar K, Fagrell B, Ostergren J, Jorneskog $\mathrm{G}$. Transcutaneous oxygen tension and toe blood pressure as predictors for outcome of diabetic foot ulcers. Diabetes Care 1999:22:147-151.

43. Faglia E, Clerici G, Clerissi J, et al. Long-term prognosis of diabetic patients with critical limb ischemia: a population-based cohort study. Diabetes Care 2009;32:822-827.

44. Faglia E, Clerici G, Clerissi J, et al. When is a technically successful peripheral angioplasty effective in preventing above-the-ankle amputation in diabetic patients with critical limb ischaemia? Diabet Med 2007:24:823-829.

45. Conte MS. Challenges of distal bypass surgery in patients with diabetes: patient selection, techniques, and outcomes. J Am Podiatr Med Assoc 2010;100:429-438

46. Chung J, Modrall JG, Ahn C, Lavery LA, Valentine RJ. Multidisciplinary care improves amputationfree survival in patients with chronic critical limb ischemia. J Vasc Surg 2015;61:162-169 e161.

47. Collins $L$, Seraj $S$. Diagnosis and treatment of venous ulcers. Am Fam Physician 2010;81:989-996.

48. Brem H, Kirsner RS, Falanga V. Protocol for the successful treatment of venous ulcers. Am Surg 2004;188:1-8.

49. O'Donnell TF, Jr., Passman MA, Marston WA et al. Management of venous leg ulcers: clinical practice guidelines of the Society for Vascular Surgery (R) and the American Venous Forum. J Vasc Surg 2014;60:3S-59S.

50. Lipsky BA, Berendt AR, Cornia PB, et al. 2012 Infectious Diseases Society of America clinical practice guideline for the diagnosis and treatment of diabetic foot infections. Clin Infect Dis 2012;54:e132-e173.

51. Pineda C, Espinosa R, Pena A. Radiographic imaging in osteomyelitis: the role of plain radiography, computed tomography, ultrasonography, magnetic resonance imaging, and scintigraphy. Semin Plast Surg 2009;23:80-89.

52. Wagner FW, Jr. The dysvascular foot: a system for diagnosis and treatment. Foot Ankle 1981;2:64-122.

53. Armstrong DG, Lavery LA, Harkless LB. Validation of a diabetic wound classification system The contribution of depth, infection, and ischemia to risk of amputation. Diabetes Care 1998;21:855-859

54. Schaper NC. Diabetic foot ulcer classification system for research purposes: a progress report on criteria for including patients in research studies. Diabetes Metab Res Rev 2004;20 Suppl 1:S90-S95.

55. Eklof B, Rutherford RB, Bergan JJ, et al. Revision of the CEAP classification for chronic venous disorders: consensus statement. J Vasc Surg 2004;40:1248-1252 
56. National Pressure Ulcer Advisory Panel, European Pressure Ulcer Advisory Panel, Pan Pacific Pressure Injury Alliance. Prevention and Treatment of Pressure Ulcers: Quick Reference Guide. Perth, Australia: Cambridge Media, 2014.

57. Oyibo SO, Jude EB, Tarawneh I, Nguyen HC, Harkless LB, Boulton AJ. A comparison of two diabetic foot ulcer classification systems: the Wagner and the University of Texas wound classification systems. Diabetes Care 2001;24:84-88.

58. Kaiser M, Yafi A, Cinat M, Choi B, Durkin AJ. Noninvasive assessment of burn wound severity using optical technology: a review of current and future modalities. Burns 2011;37:377-386.

59. Khan F, Newton DJ. Laser Doppler imaging in the investigation of lower limb wounds. Int $\mathrm{J}$ Low Extrem Wounds 2003;2:74-86.

60. Kuck M, Strese H, Alawi SA, et al. Evaluation of optical coherence tomography as a non-invasive diagnostic tool in cutaneous wound healing. Skin Res Technol 2014;20:1-7.

61. Xu RX, Huang K, Oin R, et al. Dual-mode imaging of cutaneous tissue oxygenation and vascular function. J Vis Exp 2010:2095.

62. Yudovsky D, Nouvong A, Pilon L. Hyperspectral imaging in diabetic foot wound care. J Diabetes Sci Technol 2010;4:1099-1113.

63. Apelqvist J, Bakker K, van Houtum WH, Schaper NC, International Working Group on the Diabetic Foot Editorial B. Practical guidelines on the management and prevention of the diabetic foot: based upon the International Consensus on the Diabetic Foot (2007) Prepared by the International Working Group on the Diabetic Foot. Diabetes Metab Res Rev 2008;24 Suppl 1:S181-S187.

64. Snyder RJ, Kirsner RS, Warriner RA, 3rd, Lavery LA, Hanft JR, Sheehan P. Consensus recommendations on advancing the standard of care for treating neuropathic foot ulcers in patients with diabetes. Ostomy Wound Manage 2010;56:S1-S24.

65. Molnar JA, Underdown MJ, Clark WA. Nutrition and chronic wounds. Adv Wound Care 2014;3:663-681.

66. Patel GK. The role of nutrition in the management of lower extremity wounds. Int J Low Extrem Wounds 2005;4:12-22.

67. Bradbury AW, Adam DJ, Bell J, et al. Multicentre randomised controlled trial of the clinical and cost-effectiveness of a bypass-surgery-first versus a balloon-angioplasty-first revascularisation strategy for severe limb ischaemia due to infrainguinal disease. The Bypass versus Angioplasty in Severe Ischaemia of the Leg (BASIL) trial. Health Technol Assess 2010;14:1-210, iii-iv.

68. Mills JL, Sr., Conte MS, Armstrong DG, et al. The Society for Vascular Surgery Lower Extremity Threatened Limb Classification System: risk stratification based on wound, ischemia, and foot infection (WIfI). J Vasc Surg 2014;59:220234.e221-e222.

69. Londahl M, Katzman P, Nilsson A, Hammarlund C. Hyperbaric oxygen therapy facilitates healing of chronic foot ulcers in patients with diabetes. Diabetes Care 2010;33:998-1003.

70. Kranke P, Bennett M, RoeckI-Wiedmann I, Debus S. Hyperbaric oxygen therapy for chronic wounds. Cochrane Database Syst Rev 2004;4:CD004123.

71. Leslie CA, Sapico FL, Ginunas VJ, Adkins RH. Randomized controlled trial of topical hyperbaric oxygen for treatment of diabetic foot ulcers. Diabetes Care 1988;11:111-115.

72. Gordillo GM, Sen CK. Evidence-based recommendations for the use of topical oxygen therapy in the treatment of lower extremity wounds. Int J Low Extrem Wounds 2009;8:105-111.

73. Pecoraro RE, Reiber GE, Burgess EM. Pathways to diabetic limb amputation. Basis for prevention. Diabetes Care 1990;13:513-521.

74. Faglia E, Clerici G, Caminiti M, Quarantiello A, Gino $M$, Morabito A. The role of early surgical debridement and revascularization in patients with diabetes and deep foot space abscess: retrospective review of 106 patients with diabetes. J Foot Ankle Surg 2006;45:220-226.

75. Panuncialman J, Falanga V. The science of wound bed preparation. Clin Plast Surg 2007;34:621-632.

76. Lazaro-Martinez JL, Aragon-Sanchez J, GarciaMorales E. Antibiotics versus conservative surgery for treating diabetic foot osteomyelitis: a randomized comparative trial. Diabetes Care 2014;37:789-795.

77. Granick M, Boykin J, Gamelli R, Schultz G, Tenenhaus $M$. Toward a common language: surgical wound bed preparation and debridement. Wound Repair Regen 2006;14 Suppl 1:S1-S10.

78. Leaper DJ, Schultz G, Carville K, Fletcher J, Swanson T, Drake R. Extending the TIME concept: what have we learned in the past 10 years?. Int Wound J 2012;9 Suppl 2:1-19.

79. Ligresti C, Bo F. Wound bed preparation of difficult wounds: an evolution of the principles of TIME. Int Wound J 2007:4:21-29.

80. Schultz G, Mozingo D, Romanelli M, Claxton K. Wound healing and TIME; new concepts and scientific applications. Wound Repair Regen 2005; 13:S1-S11.

81. Cardinal M, Eisenbud DE, Armstrong DG, et al. Serial surgical debridement: a retrospective study on clinical outcomes in chronic lower extremity wounds. Wound Repair Regen 2009;17:306-311.

82. Steed DL, Donohoe D, Webster MW, Lindsley L. Effect of extensive debridement and treatment on the healing of diabetic foot ulcers. Diabetic Ulcer Study Group. J Am Coll Surg 1996;183:61-64.

83. Piaggesi A, Schipani E, Campi F, et al. Conservative surgical approach versus non-surgical management for diabetic neuropathic foot ulcers: a randomized trial. Diabet Med 1998;15:412-417.

84. Falanga V, Brem H, Ennis WJ, Wolcott R, Gould $\mathrm{LJ}$, Ayello EA. Maintenance debridement in the treatment of difficult-to-heal chronic wounds. Recommendations of an expert panel. Ostomy Wound Manage 2008;Suppl:2-13; quiz 14-15.
85. Sherman RA. Maggot versus conservative debridement therapy for the treatment of pressure ulcers. Wound Repair Regen 2002;10:208-214.

86. Tian X, Liang XM, Song GM, Zhao Y, Yang XL. Maggot debridement therapy for the treatment of diabetic foot ulcers: a meta-analysis. J Wound Care 2013;22:462-469.

87. Steed DL, Attinger C, Colaizzi T, et al. Guidelines for the treatment of diabetic ulcers. Wound Repair Regen 2006;14:680-692.

88. Brem H, Tomic-Canic M. Cellular and molecular basis of wound healing in diabetes. J Clin Invest 2007;117:1219-1222.

89. Snyder RJ, Frykberg RG, Rogers LC, et al. The management of diabetic foot ulcers through optimal off-loading building consensus guidelines and practical recommendations to improve outcomes. $J$ Am Podiatr Med Assoc 2014;104:555-567.

90. Armstrong DG, Nguyen HC, Lavery LA, van Schie $\mathrm{CH}$, Boulton AJ, Harkless LB. Off-loading the diabetic foot wound: a randomized clinical trial. Diabetes Care 2001;24:1019-1022.

91. Cavanagh PR, Bus SA. Off-loading the diabetic foot for ulcer prevention and healing. J Am Podiatr Med Assoc 2010;100:360-368.

92. Lewis J, Lipp A. Pressure-relieving interventions for treating diabetic foot ulcers. Cochrane Database Syst Rev 2013;1:CD002302.

93. Katz IA, Harlan A, Miranda-Palma B, et al. A randomized trial of two irremovable off-loading devices in the management of plantar neuropathic diabetic foot ulcers. Diabetes Care 2005;28:555-559.

94. Dolibog P, Franek A, Taradaj J, et al. A randomized, controlled clinical pilot study comparing three types of compression therapy to treat venous leg ulcers in patients with superficial and/or segmental deep venous reflux. Ostomy Wound Manage 2013;59:22-30.

95. Kimmel H, Robin A. An evidence-based algorithm for treating venous leg ulcers utilizing the cochrane database of systematic reviews. Wounds 2013;25:242-250.

96. Frykberg RG, Bevilacqua NJ, Habershaw G. Surgical off-loading of the diabetic foot. J Vasc Surg 2010;52:44S-58S.

97. Armstrong DG, Frykberg RG. Classifying diabetic foot surgery: toward a rational definition. Diabet Med 2003;20:329-331.

98. La Fontaine J, Lavery LA, Hunt NA, Murdoch DP. The role of surgical off-loading to prevent recurrent ulcerations. Int J Low Extrem Wounds 2014;13:320-334.

99. Armstrong DG, Lavery LA, Stern S, Harkless LB. Is prophylactic diabetic foot surgery dangerous? J Foot Ankle Surg 1996;35:585-589.

100. Belczyk RJ, Rogers LC, Andros G, Wukich DK, Burns PR. External fixation techniques for plastic and reconstructive surgery of the diabetic foot. Clin Podiatr Med Surg 2011;28:649-660. 
101. Blume PA, Donegan R, Schmidt BM. The role of plastic surgery for soft tissue coverage of the diabetic foot and ankle. Clin Podiatr Med Surg 2014;31:127-150.

102. Sayner LR, Rosenblum BI, Giurini JM. Elective surgery of the diabetic foot. Clin Podiatr Med Surg 2003;20:783-792.

103. Laborde JM. Treatment of diabetic foot ulcers with tendon lengthening. Am Fam Physician 2009;80:1351; author reply 1351.

104. Lin SS, Lee TH, Wapner KL. Plantar forefoot ulceration with equinus deformity of the ankle in diabetic patients: the effect of tendo-Achilles lengthening and total contact casting. Orthopedics 1996;19:465-475.

105. Armstrong DG, Lavery LA, Frykberg RG, Wu SC, Boulton AJ. Validation of a diabetic foot surgery classification. Int Wound J 2006;3:240-246.

106. Piaggesi A, Goretti C, Mazzurco S, etal. A randomized controlled trial to examine the efficacy and safety of a new super-oxidized solution for the management of wide postsurgical lesions of the diabetic foot. Int $J$ Low Extrem Wounds 2010;9:10-15.

107. Carter MJ, Tingley-Kelley K, Warriner RA, 3rd. Silver treatments and silver-impregnated dressings for the healing of leg wounds and ulcers: a systematic review and meta-analysis. J Am Acad Dermatol 2010;63:668-679.

108. Chambers H, Dumville JC, Cullum N. Silver treatments for leg ulcers: a systematic review. Wound Repair Regen 2007;15:165-173.

109. Bakker K, Apelqvist J, Schaper NC. Practical guidelines on the management and prevention of the diabetic foot 2011. Diabetes Metab Res Rev 2012;28 Suppl 1:225-231.

110. American Diabetes Association. Consensus development conference on diabetic foot wound care. Diabetes Care 1999;22:1354.

111. Sheehan P, Jones P, Caselli A, Giurini JM, Veves A. Percent change in wound area of diabetic foot ulcers over a 4-week period is a robust predictor of complete healing in a 12-week prospective trial. Diabetes Care 2003;26:1879-1882.

112. Veves A, Sheehan P, Pham HT. A randomized, controlled trial of Promogran (a collagen/oxidized regenerated cellulose dressing) vs standard treatment in the management of diabetic foot ulcers. Arch Surg 2002;137:822-827.

113. Cardinal M, Eisenbud DE, Phillips T, Harding K. Early healing rates and wound area measurements are reliable predictors of later complete wound closure. Wound Repair Regen 2008;16:19-22.

114. Boulton AJ. The diabetic foot: from art to science. The 18th Camillo Golgi lecture. Diabetologia 2004;47:1343-1353.

115. Snyder RJ, Cardinal M, Dauphinee DM, Stavosky J. A post-hoc analysis of reduction in diabetic foot ulcer size at 4 weeks as a predictor of healing by 12 weeks. Ostomy Wound Manage 2010;56:44-50.

116. Mulder G, Tenenhaus M, D'Souza GF. Reduction of diabetic foot ulcer healing times through use of advanced treatment modalities. Int J Low Extrem Wounds 2014:13:335-346.

117. Kirsner RS, Warriner R, Michela M, Stasik L, Freeman K. Advanced biological therapies for diabetic foot ulcers. Arch Dermatol 2010;146:857-862.

118. Wu SC, Marston W, Armstrong DG. Wound care: the role of advanced wound healing technologies. J Vasc Surg 2010;52:59S-66S.

119. Armstrong DG, Boulton AJ, Banwell P. Negative pressure wound therapy in treatment of diabetic foot wounds: a marriage of modalities. Ostomy Wound Manage 2004;50:9-12.

120. Banwell PE. Topical negative pressure therapy in wound care. J Wound Care 1999;8:79-84.

121. Morykwas MJ, Simpson J, Punger K, Argenta A, Kremers L, Argenta J. Vacuum-assisted closure: state of basic research and physiologic foundation. Plast Reconstr Surg 2006;117:121S-126S.

122. Petrie N, Potter M, Banwell P. The management of lower extremity wounds using topical negative pressure. Int J Low Extrem Wounds 2003;2:198-206.

123. Smith APS, Whittington K, Frykberg RG, DeLeon J. Negative pressure wound therapy. In: Krasner $\mathrm{DL}$, Rodeheaver GT, Sibbald RG, Woo KY, eds. Chronic Wound Care 5: A Clinical Source Book for Healthcare Professionals. Malvern, PA: HMP Communications, 2012:271-299.

124. Argenta LC, Morykwas MJ. Vacuum-assisted closure: a new method for wound control and treatment: clinical experience. Ann Plast Surg 1997;38:563-576; discussion 577

125. Morykwas MJ, Argenta LC, Shelton-Brown El, McGuirt W. Vacuum-assisted closure: a new method for wound control and treatment: animal studies and basic foundation. Ann Plast Surg 1997;38:553-562.

126. Andros G, Armstrong DG, Attinger $C E$, et al. Consensus statement on negative pressure wound therapy (V.A.C. Therapy) for the management of diabetic foot wounds. Ostomy Wound Manage 2006;Suppl:1-32.

127. Isaac AL, Armstrong DG. Negative pressure wound therapy and other new therapies for diabetic foot ulceration: the current state of play. Med Clin North Am 2013:97:899-909.

128. Dalla Paola L. Diabetic foot wounds: the value of negative pressure wound therapy with instillation. Int Wound J 2013;10 Suppl 1:25-31.

129. Ubbink DT, Westerbos SJ, Evans D, Land L, Vermeulen $H$. Topical negative pressure for treating chronic wounds. Cochrane Database Syst Rev 2008:CD001898.

130. Armstrong DG, Lavery LA. Negative pressure wound therapy after partial diabetic foot amputation: a multicentre, randomised controlled trial. Lancet 2005:366:1704-1710.

131. Blume PA, Walters J, Payne W, Ayala J, Lantis J. Comparison of negative pressure wound therapy using vacuum-assisted closure with advanced moist wound therapy in the treatment of diabetic foot ulcers: a multicenter randomized controlled trial. Diabetes Care 2008;31:631-636.
132. Ubbink DT, Westerbos SJ, Nelson EA, Vermeulen $\mathrm{H}$. A systematic review of topical negative pressure therapy for acute and chronic wounds. Br J Surg 2008;95:685-692.

133. Saxena V, Hwang CW, Huang S, Eichbaum O, Ingber D, Orgill DP. Vacuum-assisted closure: microdeformations of wounds and cell proliferation. Plast Reconstr Surg 2004;114:1086-1096; discussion 1097-1088

134. Scherer SS, Pietramaggiori G, Mathews JC, Prsa MJ, Huang S, Orgill DP. The mechanism of action of the vacuum-assisted closure device. Plast Reconstr Surg 2008;122:786-797.

135. Isaac AL, Rose J, Armstrong DG. Mechanically powered negative pressure wound therapy as a bolster for skin grafting. Plast Reconstr Surg Glob Open 2014;2:e103.

136. Bollero D, Degano K, Gangemi EN, Aloj D, Malvasio V, Stella M. Long-term follow-up of negative pressure wound therapy with instillation: a limb salvage procedure? Int Wound J 2014 [Epub ahead of print]; DOI: 10.1111/iwj.12373.

137. Kim PJ, Attinger CE, Steinberg JS, et al. The impact of negative-pressure wound therapy with instillation compared with standard negativepressure wound therapy: a retrospective, historical, cohort, controlled study. Plast Reconstr Surg 2014;133:709-716.

138. Wolvos TA. Negative pressure wound therapy with instillation: the current state of the art Surg Technol Int 2014;24:53-62.

139. Fong KD, Marston WA. SNaP wound care system: ultraportable mechanically powered negative pressure wound therapy. Adv Wound Care 2012;1:41-43.

140. Bohn G. Mechanically powered ambulatory negative pressure wound therapy device for treatment of a colostomy takedown site. J Wound Ostomy Continence Nurs 2013;40:315-317.

141. Armstrong DG, Marston WA, Reyzelman AM, Kirsner RS. Comparative effectiveness of mechanically and electrically powered negative pressure wound therapy devices: a multicenter randomized controlled trial. Wound Repair Regen 2012;20:332-341.

142. Armstrong DG, Marston WA, Reyzelman AM, Kirsner RS. Comparison of negative pressure wound therapy with an ultraportable mechanically powered device vs. traditional electrically powered device for the treatment of chronic lower extremity ulcers: a multicenter randomized-controlled trial. Wound Repair Regen 2011;19:173-180.

143. Neiderer K, Martin B, Hoffman S, Jolley D, Dancho J. A mechanically powered negative pressure device used in conjunction with a bioengineered cell-based product for the treatment of pyoderma gangrenosum: a case report. Ostomy Wound Manage 2012;58:44-48.

144. Fife CE, Buyukcakir C, Otto G, Sheffield P, Love T, Warriner $R, 3 r d$. Factors influencing the outcome of lower-extremity diabetic ulcers treated with hyperbaric oxygen therapy. Wound Repair Regen 2007;15:322-331. 
145. Fife CE, Hopf H. Discussion. Hyperbaric oxygen: its mechanisms and efficacy. Plast Reconstr Surg 2011;127 Suppl 1:142S-143S.

146. Londahl M. Hyperbaric oxygen therapy as adjunctive treatment for diabetic foot ulcers. Int $\mathrm{J}$ Low Extrem Wounds 2013;12:152-157.

147. Roeckl-Wiedmann I, Bennett M, Kranke P. Systematic review of hyperbaric oxygen in the management of chronic wounds. Br J Surg 2005;92: 24-32.

148. Stoekenbroek RM, Santema TB, Legemate DA, Ubbink DT, van den Brink A, Koelemay MJ. Hyperbaric oxygen for the treatment of diabetic foot ulcers: a systematic review. Eur J Vasc Endovasc Surg 2014:47:647-655.

149. Wunderlich RP, Peters EJ, Lavery LA. Systemic hyperbaric oxygen therapy: lower-extremity wound healing and the diabetic foot. Diabetes Care 2000;23:1551-1555.

150. Zamboni WA, Browder LK, Martinez J. Hyperbaric oxygen and wound healing. Clin Plast Surg 2003;30:67-75.

151. Abidia A, Laden G, Kuhan G, et al. The role of hyperbaric oxygen therapy in ischaemic diabetic lower extremity ulcers: a double-blind randomised-controlled trial. Eur J Vasc Endovasc Surg 2003;25:513-518.

152. Baroni G, Porro T, Faglia E, et al. Hyperbaric oxygen in diabetic gangrene treatment. Diabetes Care 1987;10:81-86.

153. Faglia E, Favales F, Aldeghi A, et al. Adjunctive systemic hyperbaric oxygen therapy in treatment of severe prevalently ischemic diabetic foot ulcer. A randomized study. Diabetes Care 1996;19:13381343.

154. Hammarlund C, Sundberg T. Hyperbaric oxygen reduced size of chronic leg ulcers: a randomized double-blind study. Plast Reconstr Surg 1994;93:829-833; discussion 834.

155. Kessler L, Bilbault P, Ortega F, et al. Hyperbaric oxygenation accelerates the healing rate of nonischemic chronic diabetic foot ulcers: a prospective randomized study. Diabetes Care 2003;26:2378-2382.

156. Zamboni WA, Wong HP, Stephenson LL, Pfeifer MA. Evaluation of hyperbaric oxygen for diabetic wounds: a prospective study. Undersea Hyperb Med 1997;24:175-179.

157. Kranke P, Bennett MH, Martyn-St James M, Schnabel A, Debus SE. Hyperbaric oxygen therapy for chronic wounds. Cochrane Database Syst Rev 2012;4:CD004123.

158. Margolis DJ, Gupta J, Hoffstad 0, et al. Lack of effectiveness of hyperbaric oxygen therapy for the treatment of diabetic foot ulcer and the prevention of amputation: a cohort study. Diabetes Care 2013;36:1961-1966.

159. Sen CK. Wound healing essentials: let there be oxygen. Wound Repair Regen 2009;17:1-18.

160. Tawfick WA, Sultan S. Technical and clinical outcome of topical wound oxygen in comparison to conventional compression dressings in the management of refractory nonhealing venous ulcers. Vasc Endovascular Surg 2013;47:30-37.

161. Fries RB, Wallace WA, Roy $S$, et al. Dermal excisional wound healing in pigs following treatment with topically applied pure oxygen. Mutat Res 2005;579:172-181.

162. Blackman E, Moore C, Hyatt J, Railton R, Frye C. Topical wound oxygen therapy in the treatment of severe diabetic foot ulcers: a prospective controlled study. Ostomy Wound Manage 2010;56:24-31.

163. Gordillo GM, Roy S, Khanna S, et al. Topical oxygen therapy induces vascular endothelial growth factor expression and improves closure of clinically presented chronic wounds. Clin Exp Pharmacol Physiol 2008:35:957-964.

164. Gordillo GM, Schlanger R, Wallace WA, Bergdall V, Bartlett R, Sen CK. Protocols for topical and systemic oxygen treatments in wound healing. Methods Enzymol 2004;381:575-585.

165. Kalliainen LK, Gordillo GM, Schlanger R, Sen CK. Topical oxygen as an adjunct to wound healing: a clinical case series. Pathophysiology 2003;9:81-87.

166. Orsted HL, Poulson R, Advisory G, et al. Evidencebased practice standards for the use of topical pressurised oxygen therapy. Int Wound J 2012;9: 271-284.

167. Said HK, Hijjawi J, Roy N, Mogford J, Mustoe T. Transdermal sustained-delivery oxygen improves epithelial healing in a rabbit ear wound model. Arch Surg 2005;140:998-1004.

168. Tawfick W, Sultan S. Does topical wound oxygen (TWO2) offer an improved outcome over conventional compression dressings (CCD) in the management of refractory venous ulcers (RVU)? A parallel observational comparative study. Eur $\mathrm{J}$ Vasc Endovasc Surg 2009;38:125-132.

169. Woo KY, Coutts PM, Sibbald RG. Continuous topical oxygen for the treatment of chronic wounds: a pilot study. Adv Skin Wound Care 2012;25: 543-547.

170. Ennis WJ, Lee C, Plummer M, Meneses P. Current status of the use of modalities in wound care: electrical stimulation and ultrasound therapy. Plast Reconstr Surg 2011;127 Suppl 1:93S-102S.

171. Graebert JK, Henzel MK, Honda KS, Bogie KM. Systemic evaluation of electrical stimulation for ischemic wound therapy in a preclinical model. Adv Wound Care 2014;3:428-437.

172. Kloth LC. Electrical stimulation technologies for wound healing. Adv Wound Care 2014;3:81-90.

173. Houghton PE, Campbell KE. Therapeutic modalities in the treatment of chronic recalcitrant wounds. In: Krasner DL, Rodeheaver GT, Sibbald RG, Woo KY, eds. Chronic Wound Care 5: A Clinical Source Book for Healthcare Professionals. Malvern, PA: HMP Communications, 2012:253-270.

174. Baker LL, Chambers R, DeMuth SK, Villar F. Effects of electrical stimulation on wound healing in patients with diabetic ulcers. Diabetes Care 1997;20:405-412.
175. Kloth LC. Electrical stimulation for wound healing: a review of evidence from in vitro studies, animal experiments, and clinical trials. Int J Low Extrem Wounds 2005;4:23-44.

176. McCulloch J. Electrical stimulation in wound repair. In: Yee BY, ed. The Wound Management Manual. New York, NY: McGraw Hill, 2005:80-89.

177. Fernandez-Chimeno M, Houghton PE, Holey L. Electrical stimulation for chronic wounds (Protocol). Cochrane Database Syst Rev 2004:CD004550.

178. Frykberg R, Tierney E, Tallis A, Klotzbach T. Cell proliferation induction: healing chronic wounds through low-energy pulsed radiofrequency. Int $\mathrm{J}$ Low Extrem Wounds 2009;8:45-51.

179. Frykberg RG, Driver VR, Lavery LA, Armstrong DG, Isenberg RA. The use of pulsed radio frequency energy therapy in treating lower extremity wounds: results of a retrospective study of a wound registry. Ostomy Wound Manage 2011;57:22-29.

180. Moffett J, Griffin NE, Ritz MC, George FR. Pulsed radio frequency energy field treatment of cells in culture results in increased expression of genes involved in the inflammation phase of lower extremity diabetic wound healing. J Diabet Foot Complications 2010;2:57-64.

181. Wendelken ME, Markowitz L, Alvarez OM. A closer look at ultrasonic debridement. Podiatry Today 2010;23:23-28.

182. Amini S, Shojaeefard A, Annabestani Z, et al. Low-frequency ultrasound debridement in patients with diabetic foot ulcers and osteomyelitis. Wounds 2013;25:193-198.

183. Stanisic MM, Provo BJ, Larson DL, Kloth LC. Wound debridement with $25 \mathrm{kHz}$ ultrasound. Adv Skin Wound Care 2005;18:484-490

184. Ennis WJ, Foremann P, Mozen N, Massey J, Conner-Kerr T, Meneses P. Ultrasound therapy for recalcitrant diabetic foot ulcers: results of a randomized, double-blind, controlled, multicenter study. Ostomy Wound Manage 2005:51:24-39.

185. Ennis WJ, Valdes W, Gainer M, Meneses P. Evaluation of clinical effectiveness of MIST ultrasound therapy for the healing of chronic wounds. Adv Skin Wound Care 2006;19:437-446.

186. Kavros SJ, Liedl DA, Boon AJ, Miller JL, Hobbs $\mathrm{JA}$, Andrews KL. Expedited wound healing with noncontact, low-frequency ultrasound therapy in chronic wounds: a retrospective analysis. Adv Skin Wound Care 2008:21:416-423.

187. Kavros SJ, Miller JL, Hanna SW. Treatment of ischemic wounds with noncontact, low-frequency ultrasound: the Mayo clinic experience, 20042006. Adv Skin Wound Care 2007;20:221-226.

188. Kavros SJ, Schenck EC. Use of noncontact lowfrequency ultrasound in the treatment of chronic foot and leg ulcerations: a 51-patient analysis. J Am Podiatr Med Assoc 2007;97:95-101.

189. Dymarek R, Halski T, Ptaszkowski K, Slupska L, Rosinczuk J, Taradaj J. Extracorporeal shock wave therapy as an adjunct wound treatment: a 
systematic review of the literature. Ostomy Wound Manage 2014;60:26-39.

190. Mittermayr R, Antonic V, Hartinger J, et al. Extracorporeal shock wave therapy (ESWT) for wound healing: technology, mechanisms, and clinical efficacy. Wound Repair Regen 2012;20:456-465.

191. Wang CJ, Wu RW, Yang YJ. Treatment of diabetic foot ulcers: a comparative study of extracorporeal shockwave therapy and hyperbaric oxygen therapy. Diabetes Res Clin Pract 2011;92: 187-193.

192. Li WW, Kung EF, Li WW. Molecular therapy for wounds: modalities for stimulating angiogenesis and granulation. In: Yee BY, ed. The Wound Management Manual. New York, NY: McGraw Hill, 2005:17-43.

193. Knighton DR, Ciresi K, Fiegel VD, Schumerth S, Butler E, Cerra F. Stimulation of repair in chronic, nonhealing, cutaneous ulcers using plateletderived wound healing formula. Surg Gynecol Obstet 1990;170:56-60.

194. Knighton DR, Ciresi KF, Fiegel VD, Austin LL, Butler EL. Classification and treatment of chronic nonhealing wounds. Successful treatment with autologous platelet-derived wound healing factors (PDWHF). Ann Surg 1986;204:322-330.

195. Knighton DR, Doucette M, Fiegel VD, Ciresi K, Butler $E$, Austin L. The use of platelet derived wound healing formula in human clinical trials. Prog Clin Biol Res 1988;266:319-329.

196. Steed DL, Goslen JB, Holloway GA, Malone JM, Bunt TJ, Webster MW. Randomized prospective double-blind trial in healing chronic diabetic foot ulcers. CT-102 activated platelet supernatant, topical versus placebo. Diabetes Care 1992;15:1598-1604.

197. Frykberg RG, Driver VR, Carman D, et al. Chronic wounds treated with a physiologically relevant concentration of platelet-rich plasma gel: a prospective case series. Ostomy Wound Manage 2010;56:36-44.

198. Driver VR, Hanft J, Fylling CP, Beriou JM, Autologel Diabetic Foot Ulcer Study G. A prospective, randomized, controlled trial of autologous platelet-rich plasma gel for the treatment of diabetic foot ulcers. Ostomy Wound Manage 2006;52:68-70, 72, 74 passim.

199. Ramos-Torrecillas J, Luna-Bertos E, GarciaMartinez O, Ruiz C. Clinical utility of growth factors and platelet-rich plasma in tissue regeneration: a review. Wounds 2014;26:2017-2213.

200. Smiell JM, Wieman TJ, Steed DL, Perry BH, Sampson AR, Schwab BH. Efficacy and safety of becaplermin (recombinant human plateletderived growth factor-BB) in patients with nonhealing, lower extremity diabetic ulcers: a combined analysis of four randomized studies. Wound Repair Regen 1999;7:335-346.

201. Steed DL. Clinical evaluation of recombinant human platelet-derived growth factor for the treatment of lower extremity diabetic ulcers. Diabetic Ulcer Study Group. J Vasc Surg 1995;21:71-78; discussion 79-81.
202. Wieman TJ. Clinical efficacy of becaplermin (rhPDGF-BB) gel. Becaplermin Gel Studies Group. Am J Surg 1998;176:74S-79S.

203. Wieman TJ, Smiell JM, Su Y. Efficacy and safety of a topical gel formulation of recombinant human platelet-derived growth factor-BB (becaplermin) in patients with chronic neuropathic diabetic ulcers. A phase III randomized placebo-controlled doubleblind study. Diabetes Care 1998;21:822-827.

204. Margolis DJ, Bartus C, Hoffstad D, Malay S, Berlin JA. Effectiveness of recombinant human platelet-derived growth factor for the treatment of diabetic neuropathic foot ulcers. Wound Repair Regen 2005;13:531-536.

205. Falanga V, Eaglstein WH, Bucalo B, Katz MH, Harris B, Carson P. Topical use of human recombinant epidermal growth factor (h-EGF) in venous ulcers. J Dermatol Surg Oncol 1992;18:604-606.

206. Fernandez-Montequin JI, Infante-Cristia E, Valenzuela-Silva $\mathrm{C}$, et al. Intralesional injections of Citoprot-P (recombinant human epidermal growth factor) in advanced diabetic foot ulcers with risk of amputation. Int Wound J 2007;4:333-343.

207. Fernandez-Montequin JI, Valenzuela-Silva CM, Diaz OG, et al. Intra-lesional injections of recombinant human epidermal growth factor promote granulation and healing in advanced diabetic foot ulcers: multicenter, randomised, placebo-controlled, double-blind study. Int Wound J 2009;6:432-443.

208. Gomez-Villa R, Aguilar-Rebolledo F, LozanoPlatonoff $A$, et al. Efficacy of intralesional recombinant human epidermal growth factor in diabetic foot ulcers in Mexican patients: a randomized double-blinded controlled trial. Wound Repair Regen 2014;22:497-503.

209. Hong JP, Jung HD, Kim YW. Recombinant human epidermal growth factor (EGF) to enhance healing for diabetic foot ulcers. Ann Plast Surg 2006;56:394-398; discussion 399-400.

210. Mohan VK. Recombinant human epidermal growth factor (REGEN-D 150): effect on healing of diabetic foot ulcers. Diabetes Res Clin Pract 2007;78:405-411.

211. Singla S, Garg R, Kumar A, Gill C. Efficacy of topical application of beta urogastrone (recombinant human epidermal growth factor) in Wagner's Grade 1 and 2 diabetic foot ulcers: comparative analysis of 50 patients. J Nat Sci Biol Med 2014;5:273-277.

212. Valenzuela-Silva $C M$, Tuero-Iglesias AD, GarciaIglesias E, et al. Granulation response and partial wound closure predict healing in clinical trials on advanced diabetes foot ulcers treated with recombinant human epidermal growth factor. Diabetes Care 2013;36:210-215.

213. Tsang MW, Wong WK, Hung CS, et al. Human epidermal growth factor enhances healing of diabetic foot ulcers. Diabetes Care 2003;26:1856-1861.

214. Morimoto N, Yoshimura K, Niimi M, et al. Novel collagen/gelatin scaffold with sustained release of basic fibroblast growth factor: clinical trial for chronic skin ulcers. Tissue Eng Part A 2013;19:1931-1940.

215. O'Goshi K, Tagami H. Basic fibroblast growth factor treatment for various types of recalcitrant skin ulcers: reports of nine cases. J Dermatol Treat 2007;18:375-381.

216. Ohura T, Nakajo T, Moriguchi T, et al. Clinical efficacy of basic fibroblast growth factor on pressure ulcers: case-control pairing study using a new evaluation method. Wound Repair Regen 2011;19:542-551.

217. Robson MC, Phillips TJ, Falanga V, et al. Randomized trial of topically applied repifermin (recombinant human keratinocyte growth factor-2) to accelerate wound healing in venous ulcers. Wound Repair Regen 2001;9:347-352.

218. Yao C, Yao P, Wu H, Zha Z. Acceleration of wound healing in traumatic ulcers by absorbable collagen sponge containing recombinant basic fibroblast growth factor. Biomed Mater 2006;1:33-37.

219. Schultz GS, Davidson JM, Kirsner RS, Bornstein P, Herman IM. Dynamic reciprocity in the wound microenvironment. Wound Repair Regen 2011;19: 134-148.

220. Schultz GS, Wysocki A. Interactions between extracellular matrix and growth factors in wound healing. Wound Repair Regen 2009;17:153-162.

221. Greaves NS, Iqbal SA, Baguneid M, Bayat A. The role of skin substitutes in the management of chronic cutaneous wounds. Wound Repair Regen 2013;21:194-210.

222. Badylak SF, Freytes DO, Gilbert TW. Extracellular matrix as a biological scaffold material: structure and function. Acta Biomater 2009;5:1-13.

223. Mulder G, Harding K, Kirsner R, Lee D, Serena T. International consensus. Acellular Matrices for the Treatment of Wounds. An expert working group review. London: Wounds International, 2010.

224. Kimmel H, Rahn M, Gilbert TW. The clinical effectiveness in wound healing with extracellular matrix derived from porcine urinary bladder matrix: a case series on severe chronic wounds. J Am Col Certif Wound Spec 2010;2:55-59.

225. Lullove E. Acellular fetal bovine dermal matrix in the treatment of nonhealing wounds in patients with complex comorbidities. J Am Podiatr Med Assoc 2012;102:233-239.

226. Lun S, Irvine SM, Johnson KD, et al. A functional extracellular matrix biomaterial derived from ovine forestomach. Biomaterials 2010;31:4517-4529.

227. Mitchell KB, Gallagher JJ. Porcine bladder extracellular matrix for closure of a large defect in a burn contracture release. J Wound Care 2012;21:454-456.

228. Negron L, Lun S, May BC. Ovine forestomach matrix biomaterial is a broad spectrum inhibitor of matrix metalloproteinases and neutrophil elastase. Int Wound J 2014;11:392-397.

229. Niezgoda JA, Van Gils CC, Frykberg RG, Hodde JP. Randomized clinical trial comparing OASIS 
wound matrix to regranex gel for diabetic ulcers. Adv Skin Wound Care 2005;18:258-266.

230. Kavros SJ, Dutra T, Gonzalez-Cruz R, et al. The use of PriMatrix, a fetal bovine acellular dermal matrix, in healing chronic diabetic foot ulcers: a prospective multicenter study. Adv Skin Wound Care 2014;27:356-362.

231. Fleischli JG, Laughlin TJ, Fleischli JW. Equine pericardium collagen wound dressing in the treatment of the neuropathic diabetic foot wound: a pilot study. J Am Podiatr Med Assoc 2009;99:301-305.

232. Mostow EN, Haraway GD, Dalsing M, Hodde JP, King D; Group OVUS. Effectiveness of an extracellular matrix graft (OASIS Wound Matrix) in the treatment of chronic leg ulcers: a randomized clinical trial. J Vasc Surg 2005;41:837-843.

233. Cervelli V, Lucarini L, Cerretani $C$, et al. The use of Matriderm and autologous skin grafting in the treatment of diabetic ulcers: a case report. Int Wound J 2010;7:291-296.

234. Coban YK. Combination of negative pressure wound therapy and hyalomatrix application for soft tissue defect of the great toe. Int J Low Extrem Wounds 2012;11:155-156.

235. Gravante G, Delogu D, Giordan N, Morano G, Montone A, Esposito $G$. The use of Hyalomatrix $P A$ in the treatment of deep partial-thickness burns. J Burn Care Res 2007;28:269-274.

236. Gravante G, Sorge R, Merone A, et al. Hyalomatrix PA in burn care practice: results from a national retrospective survey, 2005 to 2006. Ann Plast Surg 2010;64:69-79.

237. Motolese A, Vignati F, Brambilla R, Cerati M, Passi A. Interaction between a regenerative matrix and wound bed in nonhealing ulcers: results with 16 cases. Biomed Res Int 2013;2013:849321.

238. Clerici G, Caminiti M, Curci V, Quarantiello A, Faglia $\mathrm{E}$. The use of a dermal substitute (integra) to preserve maximal foot length in a diabetic foot wound with bone and tendon exposure following urgent surgical debridement for an acute infection. Int J Low Extrem Wounds 2009;8:209-212.

239. Yao M, Attalla K, Ren Y, French MA, Driver VR. Ease of use, safety, and efficacy of integra bilayer wound matrix in the treatment of diabetic foot ulcers in an outpatient clinical setting: a prospective pilot study. J Am Podiatr Med Assoc 2013;103:274-280.

240. Reyzelman A, Crews RT, Moore JC, et al. Clinical effectiveness of an acellular dermal regenerative tissue matrix compared to standard wound management in healing diabetic foot ulcers: a prospective, randomised, multicentre study. Int Wound J 2009;6:196-208.

241. Winters CL, Brigido SA, Liden BA, Simmons M, Hartman JF, Wright ML. A multicenter study involving the use of a human acellular dermal regenerative tissue matrix for the treatment of diabetic lower extremity wounds. Adv Skin Wound Care 2008;21:375-381.

242. Landsman AS, Cook J, Cook E, et al. A retrospective clinical study of 188 consecutive patients to ex- amine the effectiveness of a biologically active cryopreserved human skin allograft (TheraSkin(R)) on the treatment of diabetic foot ulcers and venous leg ulcers. Foot Ankle Spec 2011;4:29-41.

243. Sanders L, Landsman AS, Landsman A, et al. A prospective, multicenter, randomized, controlled clinical trial comparing a bioengineered skin substitute to a human skin allograft. Ostomy Wound Manage 2014;60:26-38.

244. Greaves NS, Benatar B, Baguneid M, Bayat A. Single-stage application of a novel decellularized dermis for treatment-resistant lower limb ulcers: positive outcomes assessed by SIAscopy, laser perfusion, and 3D imaging, with sequential timed histological analysis. Wound Repair Regen 2013;21:813-822.

245. Yonehiro L, Burleson G, Sauer V. Use of a new acellular dermal matrix for treatment of nonhealing wounds in the lower extremities of patients with diabetes. Wounds 2013;25:340-344.

246. lorio ML, Shuck J, Attinger CE. Wound healing in the upper and lower extremities: a systematic review on the use of acellular dermal matrices. Plast Reconstr Surg 2012;130:232S-241S.

247. Capito AE, Tholpady SS, Agrawal H, Drake DB, Katz AJ. Evaluation of host tissue integration, revascularization, and cellular infiltration within various dermal substrates. Ann Plast Surg 2012;68:495-500.

248. Litwiniuk M, Grzela T. Amniotic membrane: new concepts for an old dressing. Wound Repair Regen 2014;22:451-456.

249. Koob TJ, Lim JJ, Massee M, et al. Angiogenic properties of dehydrated human amnion/chorion allografts: therapeutic potential for soft tissue repair and regeneration. Vasc Cell 2014;6:10.

250. Koob TJ, Rennert R, Zabek N, et al. Biological properties of dehydrated human amnion/chorion composite graft: implications for chronic wound healing. Int Wound J 2013;10:493-500.

251. Maan ZN, Rennert RC, Koob TJ, Januszyk M, Li WW, Gurtner GC. Cell recruitment by amnion chorion grafts promotes neovascularization. J Surg Res 2015;193:953-962.

252. Fetterolf DE, Snyder RJ. Scientific and clinical support for the use of dehydrated amniotic membrane in wound management. Wounds 2012;24:299-307.

253. Cooke M, Tan EK, Mandrycky C, He H, O'Connell J, Tseng SC. Comparison of cryopreserved amniotic membrane and umbilical cord tissue with dehydrated amniotic membrane/chorion tissue. J Wound Care 2014;23:465-474, 476.

254. Zelen CM, Poka A, Andrews J. Prospective, randomized, blinded, comparative study of injectable micronized dehydrated amniotic/chorionic membrane allograft for plantar fasciitis-a feasibility study. Foot Ankle Int 2013;34:1332-1339.

255. Werber B, Martin E. A prospective study of 20 foot and ankle wounds treated with cryopreserved amniotic membrane and fluid allograft. $J$ Foot Ankle Surg 2013;52:615-621.
256. Forbes J, Fetterolf DE. Dehydrated amniotic membrane allografts for the treatment of chronic wounds: a case series. J Wound Care 2012;21:290, 292, 294-296.

257. Mermet I, Pottier N, Sainthillier JM, et al. Use of amniotic membrane transplantation in the treatment of venous leg ulcers. Wound Repair Regen 2007;15:459-464.

258. Shah AP. Using amniotic membrane allografts in the treatment of neuropathic foot ulcers. J Am Podiatr Med Assoc 2014;104:198-202.

259. Zelen CM. An evaluation of dehydrated human amniotic membrane allografts in patients with DFUs. J Wound Care 2013;22:347-348, 350-341.

260. Zelen CM, Gould L, Serena TE, Carter MJ, Keller J, Li WW. A prospective, randomised, controlled, multi-centre comparative effectiveness study of healing using dehydrated human amnion/chorion membrane allograft, bioengineered skin substitute or standard of care for treatment of chronic lower extremity diabetic ulcers. Int Wound J 2014 [Epub ahead of print]; DOI: 10.1111/iwj.12395.

261. Zelen CM, Serena TE, Denoziere G, Fetterolf DE. A prospective randomised comparative parallel study of amniotic membrane wound graft in the management of diabetic foot ulcers. Int Wound $J$ 2013:10:502-507.

262. Zelen CM, Serena TE, Snyder RJ. A prospective, randomised comparative study of weekly versus biweekly application of dehydrated human amnion/chorion membrane allograft in the management of diabetic foot ulcers. Int Wound $\mathrm{J}$ 2014;11:122-128.

263. Eaglstein WH, Falanga V. Tissue engineering and the development of Apligraf a human skin equivalent. Adv Wound Care 1998;11:1-8.

264. Falanga V, Margolis D, Alvarez 0 , et al. Rapid healing of venous ulcers and lack of clinical rejection with an allogeneic cultured human skin equivalent. Human Skin Equivalent Investigators Group. Arch Dermatol 1998:134:293-300.

265. Eaglstein WH, Iriondo M, Laszlo K. A composite skin substitute (graftskin) for surgical wounds. A clinical experience. Dermatol Surg 1995;21:839-843.

266. Veves A, Falanga V, Armstrong DG, Sabolinski ML; Apligraf Diabetic Foot Ulcer S. Graftskin, a human skin equivalent, is effective in the management of noninfected neuropathic diabetic foot ulcers: a prospective randomized multicenter clinical trial. Diabetes Care 2001;24:290-295.

267. Edmonds M, European; Australian Apligraf Diabetic Foot Ulcer Study G. Apligraf in the treatment of neuropathic diabetic foot ulcers. Int $J$ Low Extrem Wounds 2009;8:11-18.

268. Marston WA, Sabolinski ML, Parsons NB, Kirsner RS. Comparative effectiveness of a bilayered living cellular construct and a porcine collagen wound dressing in the treatment of venous leg ulcers. Wound Repair Regen 2014;22:334-340.

269. Mansbridge J, Liu K, Patch R, Symons K, Pinney E. Three-dimensional fibroblast culture implant for the treatment of diabetic foot ulcers: meta- 
bolic activity and therapeutic range. Tissue Eng 1998:4:403-414.

270. Roberts C, Mansbridge J. The scientific basis and differentiating features of Dermagraft. Can $J$ Plast Surg 2002;10:6A-13A.

271. Naughton G, Mansbridge J, Gentzkow G. A metabolically active human dermal replacement for the treatment of diabetic foot ulcers. Artif Organs 1997;21:1203-1210.

272. Marston WA, Hanft J, Norwood P, Pollak R. The efficacy and safety of Dermagraft in improving the healing of chronic diabetic foot ulcers: results of a prospective randomized trial. Diabetes Care 2003;26:1701-1705

273. Harding K, Sumner M, Cardinal M. A prospective, multicentre, randomised controlled study of human fibroblast-derived dermal substitute (Dermagraft) in patients with venous leg ulcers. Int Wound J 2013;10:132-137.

274. Angirasa AK, Willrich A, Cooper B, Stuck R. Combining bioengineered human dermal replacement and multilayered compression dressings to manage ulcers in a person with diabetes mellitus: a case study. Ostomy Wound Manage 2006;52:60-64.

275. Frykberg R, Martin E, Tallis A, Tierney E. A case history of multimodal therapy in healing a complicated diabetic foot wound: negative pressure, dermal replacement and pulsed radio frequency energy therapies. Int Wound J 2011;8:132-139.

276. Kashefsky H, Marston W. Total contact casting combined with human fibroblast-derived dermal tissue in 15DFU patients. J Wound Care 2012;21:236, 238, 240, 242-233.

277. Martin E, Tierney E, Tallis A, Frykberg RG. Use of human fibroblast derived dermal substitute (HFDDS) to close a complex chronic wound in the presence of peripheral arterial disease. J Diabet Foot Complications 2013;5:39-43.

278. Frykberg RG, Marston WA, Cardinal M. The incidence of lower-extremity amputation and bone resection in diabetic foot ulcer patients treated with a human fibroblast-derived dermal substitute. Adv Skin Wound Care 2015;28:17-20.

279. Caplan Al. Adult mesenchymal stem cells for tissue engineering versus regenerative medicine. J Cell Physiol 2007;213:341-347.

280. Wu Y, Huang S, Enhe J, Fu X. Insights into bone marrow-derived mesenchymal stem cells safety for cutaneous repair and regeneration. Int Wound J 2012;9:586-594.

281. Maxson S, Lopez EA, Yoo D, DanilkovitchMiagkova A, Leroux MA. Concise review: role of mesenchymal stem cells in wound repair. Stem Cells Transl Med 2012;1:142-149.

282. Bajada S, Mazakova I, Richardson JB, Ashammakhi N. Updates on stem cells and their applications in regenerative medicine. J Tissue Eng Reg Med 2008;2:169-183.

283. Wu Y, Wang J, Scott PG, Tredget EE. Bone marrow-derived stem cells in wound healing: a review. Wound Repair Regen 2007;15 Suppl 1:S18-S26.

284. Murray IR, Corselli M, Petrigliano FA, Soo C, Peault B. Recent insights into the identity of mesenchymal stem cells: implications for orthopaedic applications. Bone Joint J 2014;96B:291-298.

285. Tseng SS, Lee MA, Reddi AH. Nonunions and the potential of stem cells in fracture-healing. $J$ Bone Joint Surg Am 2008;90 Suppl 1:92-98.

286. Benoit E, O'Donnell TF, Patel AN. Safety and efficacy of autologous cell therapy in critical limb ischemia: a systematic review. Cell Transplant 2013;22:545-562.

287. Rogers LC, Bevilacqua NJ, Armstrong DG. The use of marrow-derived stem cells to accelerate healing in chronic wounds. Int Wound J 2008:5:20-25.

288. Wu Y, Chen L, Scott PG, Tredget EE. Mesenchymal stem cells enhance wound healing through differentiation and angiogenesis. Stem Cells 2007;25:2648-2659.

289. Fioretti F, Lebreton-DeCoster C, Gueniche F, et al. Human bone marrow-derived cells: an attractive source to populate dermal substitutes. Wound Repair Regen 2008;16:87-94.

290. Yamaguchi Y, Yoshida S, Sumikawa Y, et al. Rapid healing of intractable diabetic foot ulcers with exposed bones following a novel therapy of exposing bone marrow cells and then grafting epidermal sheets. Br J Dermatol 2004;151:10191028.

291. Cha J, Falanga V. Stem cells in cutaneous wound healing. Clin Dermatol 2007;25:73-78.

292. Gu C, Huang S, Gao D, et al. Angiogenic effect of mesenchymal stem cells as a therapeutic target for enhancing diabetic wound healing. Int J Low Extrem Wounds 2014;13:88-93.
293. Jiang XY, Lu DB, Chen B. Progress in stem cell therapy for the diabetic foot. Diabetes Res Clin Pract 2012;97:43-50.

294. Jain P, Perakath B, Jesudason MR, Nayak S. The effect of autologous bone marrow-derived cells on healing chronic lower extremity wounds: results of a randomized controlled study. Ostomy Wound Manage 2011;57:38-44.

295. Peng Y, Huang S, Cheng B, et al. Mesenchymal stem cells: a revolution in therapeutic strategies of age-related diseases. Ageing Res Rev 2013;12:103-115.

296. Regulski M, Jacobstein DA, Petranto RD, Migliori VJ, Nair G, Pfeiffer D. A retrospective analysis of a human cellular repair matrix for the treatment of chronic wounds. Ostomy Wound Manage 2013;59:38-43.

297. Lavery LA, Fulmer J, Shebetka KA, et al. The efficacy and safety of Grafix ((R)) for the treatment of chronic diabetic foot ulcers: results of a multi-centre, controlled, randomised, blinded, clinical trial. Int Wound J 2014;11:554-560.

\section{Abbreviations and Acronyms}

$A B I=$ ankle-brachial indices

$\mathrm{AMs}=$ amniotic membranes

BMSCs $=$ bone marrow-derived stem cells

DFUs $=$ diabetic foot ulcers

$\mathrm{dHACM}=$ dehydrated human amnion/chorion membrane

$\mathrm{ECM}=$ extracellular matrix

$\mathrm{EGF}=$ epidermal growth factor

ESWT $=$ extracorporeal shock wave therapy

$\mathrm{FGF}=$ fibroblast growth factor

$\mathrm{HBOT}=$ hyperbaric oxygen therapy

HFDS = human fibroblast-derived dermal substitute

$\mathrm{LFU}=$ low-frequency ultrasound

$\mathrm{MSC}=$ mesenchymal stem cell

$\mathrm{PDGF}=$ platelet-derived growth factor

PRFE $=$ pulsed radiofrequency energy

$\mathrm{PRP}=$ platelet-rich plasma

$\mathrm{PTB}=$ probe-to-bone

$\mathrm{PUs}=$ pressure ulcers

$\mathrm{RCT}=$ randomized controlled trial

ROS $=$ reactive oxygen species

$\mathrm{RR}=$ relative risk

TGF- $\beta=$ transforming growth factor $-\beta$

$\mathrm{VEGF}=$ vascular endothelial growth factor

$\mathrm{VLUs}=$ venous leg ulcers 